Article

\title{
Design and Synthesis of New 2-Aryl-4,5-dihydro-thiazole Analogues: In Vitro Antibacterial Activities and Preliminary Mechanism of Action
}

\author{
Fangfang Tan ${ }^{1, \dagger}$, Baojun Shi ${ }^{2, \dagger}$, Jian Li ${ }^{1}$, Wenjun $\mathrm{Wu}^{2}$ and Jiwen Zhang ${ }^{1,2, *}$ \\ Received: 9 September 2015 ; Accepted: 2 November 2015 ; Published: 9 November 2015 \\ Academic Editor: Derek J. McPhee \\ 1 College of Science, Northwest Agriculture and Forestry University, Yangling 712100, China; \\ 15877653513@163.com (F.T.); lijian3773@163.com (J.L.) \\ 2 Institute of Pesticide Science, Northwest Agriculture and Forestry University, Yangling 712100, China; \\ shibaojun@nwsuaf.edu.cn (B.S.); wuwenjun@nwsuaf.edu.cn (W.W.) \\ * Correspondence: nwzjw@nwsuaf.edu.cn; Tel.: +86-29-8709-2191 \\ $\dagger$ These authors contributed equally to this work.
}

\begin{abstract}
Sixty 2-aryl-4,5-dihydrothiazoles were designed and synthesized in yields ranging from $64 \%$ to $89 \%$ from cysteine and substituted-benzonitriles via a novel metal- and catalyst-free method. The structures of the title compounds were confirmed mainly by NMR spectral data analysis. Antibacterial activity assays showed that the compounds (S)-2-(2'-hydroxyphenyl)-4-hydroxy-methyl-4,5-dihydrothiazole $\quad(7 \mathbf{h})$ and (R)-2-(2'-hydroxyphenyl)-4-hydroxymethyl-4,5-dihydro-thiazole $\left(7 \mathbf{h}^{\prime}\right)$ exhibited significant inhibition against Ralstonia solanacearum, Pseudomonas syringae pv. actinidiae, Bacillus subtilis and Bacillus cereus, with minimum inhibitory concentrations (MICs) ranging from 3.91 to $31.24 \mu \mathrm{g} \cdot \mathrm{mL}^{-1}$. The effect of substituents showed that not only electron-withdrawing groups, but also electron-donating groups could abolish the antibacterial activities unless a $2^{\prime}$-hydroxy group was introduced on the 2-aryl substituent of the 4,5-dihydrothiazole analogues. The results of scanning electron microscope (SEM) and fatty acid exposure experiments indicated that these antibacterial compounds influence fatty acid synthesis in the tested bacteria.
\end{abstract}

Keywords: synthesis; 4,5-dihydrothiazole; antibacterial activity; antibacterial mechanism

\section{Introduction}

Ralstonia solanacearum and Pseudomonas syringae pv. Actinidiae are the causes of serious bacterial diseases that pose a major threat to agricultural production worldwide [1]. Unfortunately, there have been few reports of effective bactericides against these pathogens. In the process of screening new agricultural bactericides, we found that some 2-arylthiazolines such as (S)-2-(2'-hydroxyphenyl)-4-hydroxymethyl-4,5-dihydrothiazole and (R)-2-(2'-hydroxyphenyl)-4-hydroxymethyl-4,5-dihydrothiazole exhibited potent antibacterial activities [2-5]. Inspired by these results, we wondered whether the 2-arylthiazoline scaffold could be a lead compound for agricultural bactericides. In order to investigate the bactericidal activities and clarify the inevitable structural motifs of 2-arylthiazoline analogues, sixty 2-aryl-4,5-dihydrothiazoles were then designed and synthesized.

A couple of protocols have been developed for the synthesis of 2-arylthiazoline scaffolds, which mainly include using ethyl benzimidates reacted with cysteine [6], aryl nitriles condensed with cysteine in buffered media [7], Ru-catalyzed/TBHP oxidation reactions [8], and so on [9-11]. The broad application of these methods has been hindered by the following drawbacks: long reaction 
time, high reaction temperatures $\left(>100{ }^{\circ} \mathrm{C}\right)$, tedious work-ups and the use of expensive noble metal catalysts.

We present herein the design and synthesis a series of 2-aryl-4,5-dihydrothiazolines under mild metal- and catalyst-free conditions [12] as well as their in vitro antibacterial activities against Ralstonia solanacearum ( $R$. solanacearum), Pseudomonas syringae pv. Actinidiae (P. syringae), Bacillus subtilis (B. subtilis) and Bacillus cereus (B. cereus). Furthermore, we also explore the preliminary antibacterial mechanism of compound 7 h (Figure 1).

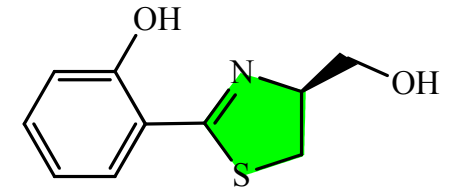

(S)-2-(2-hydroxyphenyl)-4hydroxymethyl-4,5-dihydrothiazole (7h)

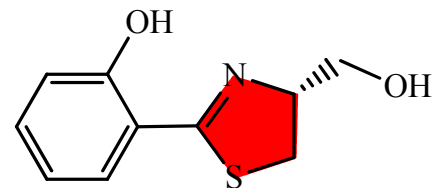

(R)-2-(2-hydroxyphenyl)-4hydroxymethyl-4,5-dihydrothiazole $\left(7 h^{\prime}\right)$

Figure 1. Chemical structures of (S)-2-(2-hydroxyphenyl)-4-hydroxymethyl-4,5-dihydrothiazole and (R)-2-(2-hydroxyphenyl)-4-hydroxymethyl-4,5-dihydrothiazole.

\section{Results and Discussion}

\subsection{Preparation of 2-Arylthiazoline Analogues}

The synthetic route to the 2-arylthiazoline analogues is depicted in Scheme 1. Aryl nitriles and methyl cysteine were used as starting materials and reacted in dry methanol in the presence of sodium carbonate and refluxed for 12-15 h to obtain methyl-2-aryl-4,5-dihydrothiazole-4-carboxylates in yields ranging from $64 \%$ to $89 \%$ [12].
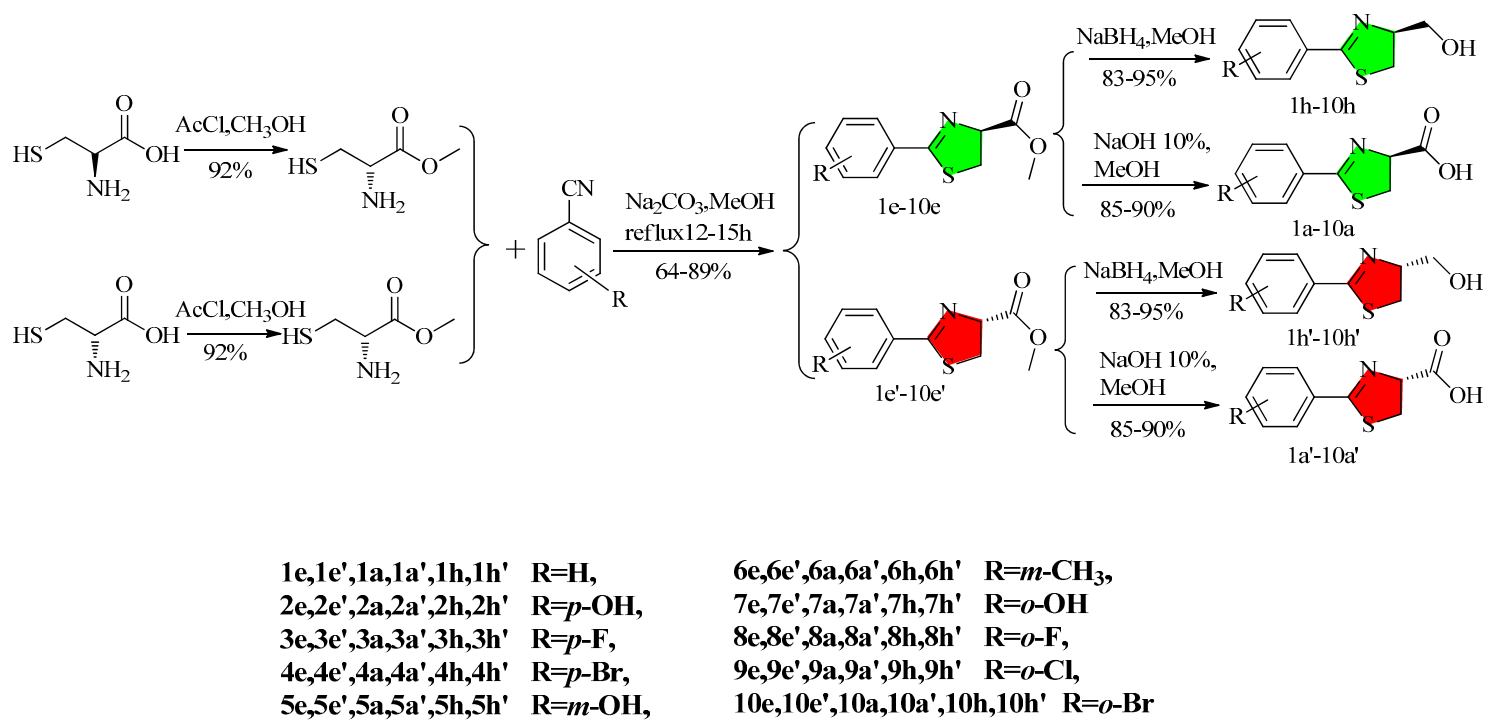

Scheme 1. Synthetic route of 2-arylthiazoline analogues.

The results suggested that ortho-substituents did not favor the reaction, in particular larger groups, such as $-\mathrm{Br}$ and $-\mathrm{Cl}$. Meanwhile the electron-withdrawing groups were better in this reaction than electron-donating ones. The carboxylates $\mathbf{1 e}-\mathbf{1 0 e}, \mathbf{1} \mathbf{e}^{\prime}-\mathbf{1 0 \mathbf { e } ^ { \prime }}$ were reduced by $\mathrm{NaBH}_{4}$ in EtOH to furnish the corresponding 2-aryl-4-hydroxymethyly-4,5-dihydrothiazoles $\mathbf{1 h}$-10h, $\mathbf{1 h}^{\prime}-\mathbf{1 0} \mathbf{h}^{\prime}$ and treated with $10 \%$ sodium hydroxide solution in $\mathrm{EtOH}$ to get the corresponding 
2-aryl-4,5-dihydrothiazole-4-carboxylic acids $\mathbf{1 a}-\mathbf{1 0 a}, \mathbf{1} \mathbf{a}^{\prime}-\mathbf{- 1 0} \mathbf{a}^{\prime}$. The structures of all the compounds were confirmed mainly by analyses of their NMR spectral and mass spectrometry data or reference to related literature [3,13-15].

\subsection{Antibacterial Activity Assays}

All compounds were evaluated for in vitro antibacterial activities against two Gram-positive bacteria-B. cereus and B. subtilis-and two Gram-negative bacteria-R. solanacearum and P. syringae. The inhibition zone diameters and minimum inhibitory concentrations (MICs), presented in Tables 1 and 2 were determined by the filter paper and double-dilution methods, respectively. However, only six 2'-hydroxyphenyl-4,5-dihydro-thiazoles showed potent antibacterial activities at the tested concentration, in particular, compounds $7 \mathbf{h}$ and $\mathbf{7 h}$ ' showed the highest antibacterial activities for all tested bacteria.

Table 1. Inhibition Zone Diameters of Six Compounds against the Tested Bacteria.

\begin{tabular}{ccccc}
\hline \multirow{2}{*}{ Compounds } & \multicolumn{4}{c}{ Diameter of Inhibition Zone $(\mathbf{m m})$ in $\mathbf{1 0} \mu \mathrm{L} /$ Disk (Mean \pm S.D.) } \\
\cline { 2 - 5 } & B. subtilis & B. cereus & R. solanacearum & P. syringae \\
\hline $\mathbf{7 a}$ & - & - & - & $11.0 \pm 0.23(+)$ \\
$\mathbf{7 a}$ & - & - & - & $10.5 \pm 0.56(+)$ \\
$\mathbf{7 e}$ & $12.3 \pm 0.02(+)$ & - & $9.1 \pm 0.11(++)$ & - \\
$7 \mathbf{e}^{\prime}$ & $11.2 \pm 0.45(+)$ & - & $9.6 \pm 0.43(++)$ & - \\
$7 \mathbf{h}$ & $20.5 \pm 0.56(+++)$ & $16.3 \pm 0.23(+++)$ & $15.5 \pm 0.13(++)$ & $18.2 \pm 0.34(+++)$ \\
$7 \mathbf{h}^{\prime}$ & $20.0 \pm 0.22(+++)$ & $16.7 \pm 0.11(+++)$ & $14.9 \pm 0.55(++)$ & $17.8 \pm 0.23(+++)$ \\
\hline
\end{tabular}

All values were means of three replicates, "+++" means transparent; "++" means clear; "+" means visible; "-" means no inhibitory effect.

Table 2. The MICs of Four Compounds against the Tested Bacteria.

\begin{tabular}{cccccc}
\hline \multirow{2}{*}{ Tested Bacteria } & \multicolumn{5}{c}{ Minimum Inhibitory Concentration $\left(\mu \mathbf{g} \cdot \mathbf{~ m L}^{-1}\right)$} \\
\cline { 2 - 6 } & $\mathbf{7 h}$ & $\mathbf{7 h}^{\prime}$ & $\mathbf{7 e}$ & $\mathbf{7 e}^{\prime}$ & Ampicillin \\
\hline R. solanacearum & 31.24 & 31.24 & $>125$ & $>125$ & $>125$ \\
P. syringae & 7.81 & 7.81 & $>125$ & $>125$ & $>125$ \\
B. cereus & 31.24 & 31.24 & $>125$ & $>125$ & 62.5 \\
B. subtilis & 3.91 & 3.91 & $>125$ & $>125$ & $>125$ \\
\hline
\end{tabular}

\subsection{Mechanism of Antibacterial Action}

\subsubsection{Fatty Acid Exposure Experiment}

The results of the fatty acid exposure experiments was similar to those of yaglingmycin, that is the diameters of inhibition zone decrease significantly with the increase of the concentration of some fatty acids. It was worth nothing that compound $7 \mathrm{~h}$ completely lost the antibacterial activity against $B$. subtilis in the presence of the long-chain saturated stearic acid, palmitic acid, and long-chain unsaturated oleic acid at the concentration of 500 ppm, 100 ppm, 1 ppm, respectively. Nevertheless, compound $7 \mathrm{~h}$ did not lose the antibacterial activity against B. subtilis in the presence of short-chain $n$-hexylic acid and these results can be found in Figure 2. 


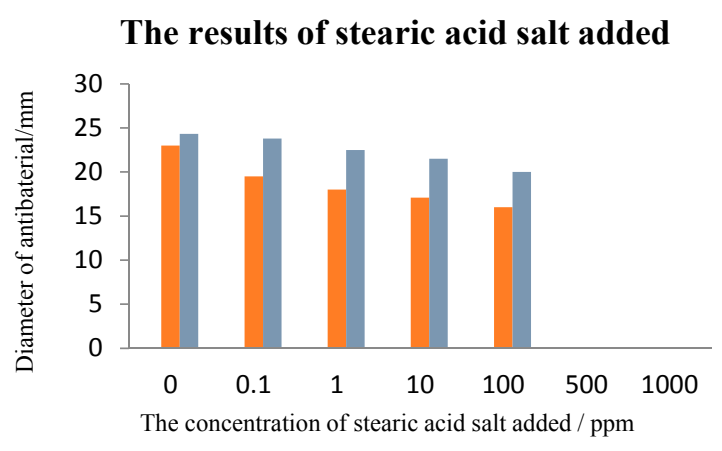

The results of hexylic acid added

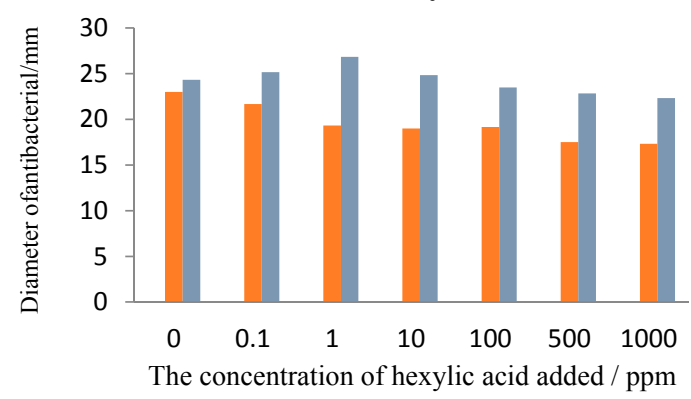

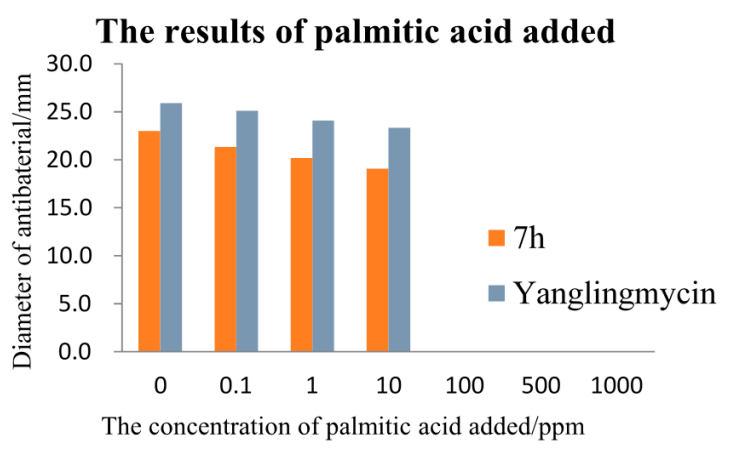

The results of sodium oleate added

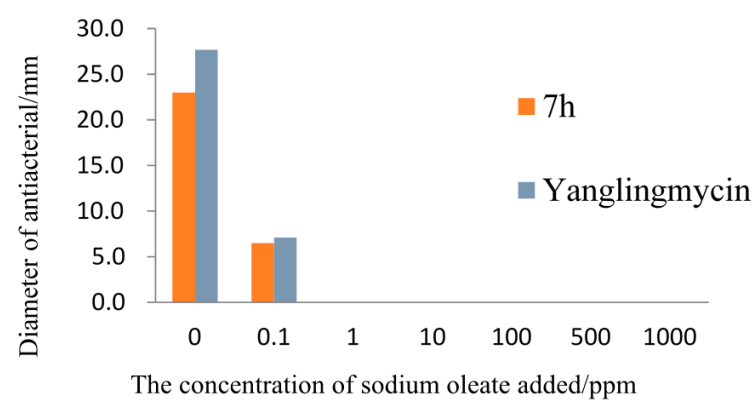

Figure 2. The fatty acid exposure experiments of compound $7 \mathbf{h}$.

\subsubsection{Scanning Electron Microscope (SEM)}

After treating B. cereus with $31.24 \mu \mathrm{g} \cdot \mathrm{mL}^{-1} 7 \mathrm{~h}$ for $3 \mathrm{~h}$, the morphological changes to the bacterial cells were observed by Scanning Electron Microscope (SEM). As shown in Figure 3, the surfaces of untreated bacterial cells were smooth and intact, while the morphology of treated cells changed dramatically. The treated cells had obvious depressions and deformations, some clear holes in the damaged cell walls and cell membranes and the cells became irregular, pitted, and shriveled. The morphological changes on the surface might result in diffusion of the contents from the cells to the outside.

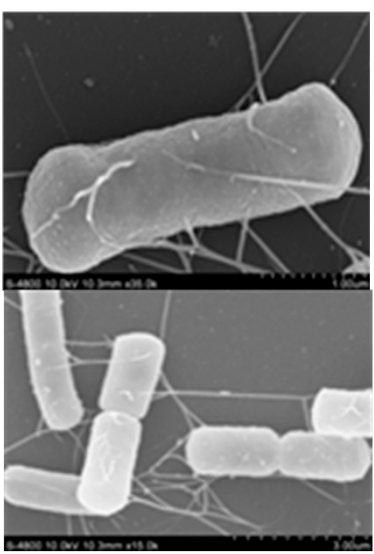

A

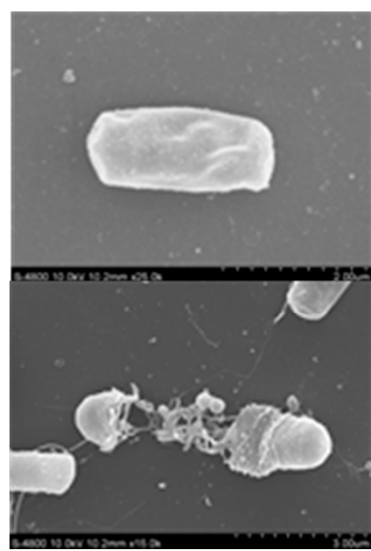

B

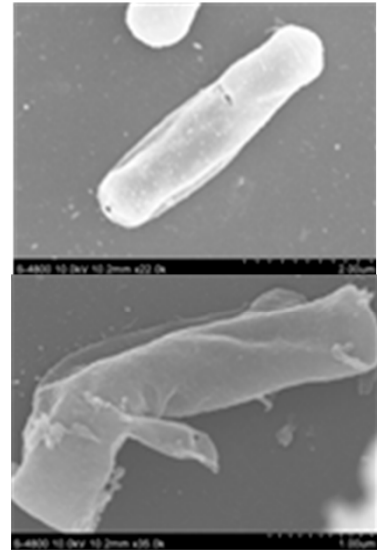

C

Figure 3. Scanning Electron Microscope (SEM) photography of B. cereus. (A) Blank control; (B) Positive control (treated with yanglingmycin); (C) Treated with Compound $\mathbf{7 h}$. 


\section{Experimental Section}

\subsection{General Information}

Solvents were of analytical reagent (AR) grade unless otherwise mentioned. TLC was performed on E. Merck 60 F254 silica gel plates. Column chromatography was carried out with 200 300 mesh silica gel (Qingdao Haiyang Co., Ltd., Qingdao, Shandong, China); compounds were eluted with the mixture solution of petroleum ether and ethyl acetate in sequence. Melting points (m.p.s, uncorrected) were measured using a Yanagimoto apparatus (Shanghai-Measuring Equipment Co., Ltd., Shanghai, China). ${ }^{1} \mathrm{H}-\mathrm{NMR}(500 \mathrm{MHz})$ and ${ }^{13} \mathrm{C}-\mathrm{NMR}(125 \mathrm{MHz})$ were obtained on a Bruker-Avance-500 spectrometer (Bruker Corporation, Switzerland) with DMSO- $d_{6}$ or $\mathrm{CDCl}_{3}$ as solvent and $\mathrm{SiMe}_{4}$ as internal standard. Mass spectra were recorded under electrospray ionization (ESI) conditions by using a Thermo LCQ Fleet instrument (Thermo Fisher, Waltham, MA, USA).

\subsection{Chemistry}

\subsubsection{Synthesis of $\mathbf{1 e}-\mathbf{1 0 e}$ and $\mathbf{1} \mathbf{e}^{\prime}-\mathbf{1 0} \mathbf{e}^{\prime}$}

Acetyl chloride $(1.6 \mathrm{~mL}, 22 \mathrm{mmol})$ was slowly added to anhydrous $\mathrm{MeOH}(100 \mathrm{~mL})$ at $0{ }^{\circ} \mathrm{C}$. The solution was then stirred for $5 \mathrm{~min}$, followed by addition of an amino acid (D-cysteine or L-cysteine) $(20 \mathrm{mmol})$. After refluxing for $6 \mathrm{~h}$, the reaction mixture was cooled to room temperature, and evaporated under reduced pressure to furnish the methyl D/L-cysteinate as a white solid in yields of $90 \%$ or $85 \%$, respectively. To the anhydrous methanol solution $(1.0 \mathrm{~mL})$ of the benzonitriles $(1.0 \mathrm{mmol})$ and anhydrous $\mathrm{Na}_{2} \mathrm{CO}_{3}(106 \mathrm{mg}, 1.0 \mathrm{mmol})$ the above synthesized methyl cysteinate $(5.0 \mathrm{mmol})$ was added, then the resulting mixture was stirred at $80^{\circ} \mathrm{C}$ for $12 \mathrm{~h}$, cooled to room temperature and concentrated. The crude mixture was purified by column chromatography on silica gel (PE/EA) to afford the desired 2-substituted-phenyl-4-methoxycarbonyl-4,5-dihydrothiazoles $\mathbf{1 e}-\mathbf{1 0 e}$ and $\mathbf{1} \mathbf{e}^{\prime}-\mathbf{1 0} \mathbf{e}^{\prime}$ in $76 \%$ to $85 \%$ yields.

(S)-2-Phenyl-4-methoxycarbonyl-4,5-dihydrothiazole (1e). White powder. m.p. $60-62{ }^{\circ} \mathrm{C} .{ }^{1} \mathrm{H}-\mathrm{NMR}$ $\left(\mathrm{CDCl}_{3}\right) \delta 7.87(\mathrm{~d}, J=7.6 \mathrm{~Hz}, 2 \mathrm{H}), 7.50-7.40(\mathrm{~m}, 3 \mathrm{H}), 5.30(\mathrm{t}, J=9.1 \mathrm{~Hz}, 1 \mathrm{H}), 3.84(\mathrm{~s}, 3 \mathrm{H}), 3.73$ $(\mathrm{dd}, J=8.8,11.0 \mathrm{~Hz}, 1 \mathrm{H}), 3.67-3.62(\mathrm{~m}, 1 \mathrm{H}) .{ }^{13} \mathrm{C}-\mathrm{NMR}\left(\mathrm{CDCl}_{3}\right) \delta 171.3,171.0,132.6,131.7,128.6 \times 2$, $128.5 \times 2,78.5,52.7$, 35.3. ESI-MS $m / z$ : Calcd for $\mathrm{C}_{11} \mathrm{H}_{11} \mathrm{NO}_{2} \mathrm{~S}: 222.05[\mathrm{M}+\mathrm{H}]^{+}$; found: 222.35 . $[\alpha]_{\mathrm{D}}^{20}+129.0^{\circ}(c=0.1, \mathrm{MeOH})$.

(S)-2-(4'-Hydroxyphenyl)-4-methoxycarbonyl-4,5-dihydrothiazole (2e). White powder. m.p. 166-168 ${ }^{\circ} \mathrm{C}$. ${ }^{1} \mathrm{H}-\mathrm{NMR}\left(\mathrm{CDCl}_{3}\right) \delta 7.69(\mathrm{~d}, J=8.5 \mathrm{~Hz}, 2 \mathrm{H}), 6.76(\mathrm{~d}, J=8.5 \mathrm{~Hz}, 2 \mathrm{H}), 5.28(\mathrm{t}, J=8.8 \mathrm{~Hz}, 1 \mathrm{H}), 3.79-3.77$ $(\mathrm{m}, 3 \mathrm{H}), 3.72-3.62(\mathrm{~m}, 2 \mathrm{H}) .{ }^{13} \mathrm{C}-\mathrm{NMR}\left(\mathrm{CDCl}_{3}\right) \delta 172.2,171.5,159.8,130.6 \times 2,124.4,115.6 \times 2$, 77.6, 52.8, 35.3. ESI-MS $m / z$ : Calcd for $\mathrm{C}_{11} \mathrm{H}_{11} \mathrm{NO}_{3} \mathrm{~S}: 238.05[\mathrm{M}+\mathrm{H}]^{+}$; found: $238.26 .[\alpha]_{\mathrm{D}}^{20}+109.6^{\circ}$ $(c=0.1, \mathrm{MeOH})$.

(S)-2-(4'-Fluorophenyl)-4-methoxycarbonyl-4,5-dihydrothiazole (3e). Yellow oil. ${ }^{1} \mathrm{H}-\mathrm{NMR}\left(\mathrm{CDCl}_{3}\right) \delta$ 7.89-7.86 (m, $2 \mathrm{H}), 7.10(\mathrm{t}, J=8.7 \mathrm{~Hz}, 2 \mathrm{H}), 5.28(\mathrm{t}, J=9.1 \mathrm{~Hz}, 1 \mathrm{H}), 3.85(\mathrm{~s}, 3 \mathrm{H}), 3.76-3.64(\mathrm{~m}, 2 \mathrm{H})$. ${ }^{13} \mathrm{C}-\mathrm{NMR}\left(\mathrm{CDCl}_{3}\right) \delta 171.2,169.7,164.8(\mathrm{~d}, J=252 \mathrm{~Hz}), 130.8,130.7,129.0,115.7,115.5,78.4,52.8,35.7$. ESI-MS $m / z$ : Calcd for $\mathrm{C}_{11} \mathrm{H}_{10} \mathrm{FNO}_{2} \mathrm{~S}: 240.04[\mathrm{M}+\mathrm{H}]^{+}$; found: $240.18 .[\alpha]_{\mathrm{D}}^{20}+57.8^{\circ}(c=0.1, \mathrm{MeOH})$.

(S)-2-(4'-Bromophenyl)-4-methoxycarbonyl-4,5-dihydrothiazole (4e). White solid. m.p. 74-76 ${ }^{\circ} \mathrm{C} .{ }^{1} \mathrm{H}-\mathrm{NMR}$ $\left(\mathrm{CDCl}_{3}\right) \delta 7.74-7.73(\mathrm{~m}, 2 \mathrm{H}), 7.56-7.54(\mathrm{~m}, 2 \mathrm{H}), 5.27(\mathrm{t}, J=9.1 \mathrm{~Hz}, 1 \mathrm{H}), 3.84(\mathrm{~s}, 3 \mathrm{H}), 3.74(\mathrm{dd}, J=8.8$, $11.0 \mathrm{~Hz}, 1 \mathrm{H}), 3.66(\mathrm{dd}, J=9.5,11.0 \mathrm{~Hz}, 1 \mathrm{H}) .{ }^{13} \mathrm{C}-\mathrm{NMR}\left(\mathrm{CDCl}_{3}\right) \delta 171.1,169.9,131.7 \times 2,131.5,130.0 \times 2$, 126.3, 78.5, 52.8, 35.6. ESI-MS $m / z$ : Calcd for $\mathrm{C}_{11} \mathrm{H}_{10} \mathrm{BrNO}_{2} \mathrm{~S}: 299.96: 301.96=1: 1[\mathrm{M}+\mathrm{H}]^{+}$; found: 299.69:301.85 =1:1. $[\alpha]_{\mathrm{D}}^{20}+7.6^{\circ}(c=0.1, \mathrm{MeOH})$.

(S)-2-(3'-Hydroxyphenyl)-4-methoxycarbonyl-4,5-dihydrothiazole (5e). Colourless oil. ${ }^{1} \mathrm{H}-\mathrm{NMR}\left(\mathrm{CDCl}_{3}\right)$ $\delta 7.37(\mathrm{~s}, 1 \mathrm{H}), 7.32(\mathrm{~d}, J=7.6 \mathrm{~Hz}, 1 \mathrm{H}), 7.22(\mathrm{t}, J=8.0 \mathrm{~Hz}, 1 \mathrm{H}), 6.96(\mathrm{dd}, J=1.9,8.2 \mathrm{~Hz}, 1 \mathrm{H}), 5.29(\mathrm{t}$, $J=9.1 \mathrm{~Hz}, 1 \mathrm{H}), 3.80(\mathrm{~s}, 3 \mathrm{H}), 3.72-3.62(\mathrm{~m}, 2 \mathrm{H}) .{ }^{13} \mathrm{C}-\mathrm{NMR}\left(\mathrm{CDCl}_{3}\right) \delta 172.2,171.3,156.2,133.4,129.8$, 
$120.9,119.4,114.9,77.9,52.8$, 35.2. ESI-MS $m / z$ : Calcd for $\mathrm{C}_{11} \mathrm{H}_{11} \mathrm{NO}_{3} \mathrm{~S}: 238.05[\mathrm{M}+\mathrm{H}]^{+}$; found: 238.22. $[\alpha]_{\mathrm{D}}^{20}+50.2^{\circ}(c=0.1, \mathrm{MeOH})$.

(S)-2-(3'-Methylphenyl)-4-methoxycarbonyl-4,5-dihydrothiazole (6e). Colourless oil. ${ }^{1} \mathrm{H}-\mathrm{NMR}\left(\mathrm{CDCl}_{3}\right) \delta$ $7.72(\mathrm{~s}, 1 \mathrm{H}), 7.64(\mathrm{~d}, J=4.1 \mathrm{~Hz}, 1 \mathrm{H}), 7.30(\mathrm{~d}, J=4.4 \mathrm{~Hz}, 2 \mathrm{H}), 5.29(\mathrm{t}, J=9.1 \mathrm{~Hz}, 1 \mathrm{H}), 3.84(\mathrm{~s}, 3 \mathrm{H})$, 3.73-3.62 (m, 2H), $2.39(\mathrm{~s}, 3 \mathrm{H}) .{ }^{13} \mathrm{C}-\mathrm{NMR}\left(\mathrm{CDCl}_{3}\right) \delta 171.4,171.2,138.3,132.6,132.5,129.0,128.4,125.9$, 78.4, 52.8, 35.3, 21.2. ESI-MS $m / z$ : Calcd for $\mathrm{C}_{12} \mathrm{H}_{13} \mathrm{NO}_{2} \mathrm{~S}: 236.07[\mathrm{M}+\mathrm{H}]^{+}$; found: 236.41 . $[\alpha]_{\mathrm{D}}^{20}+71.7^{\circ}$ $(c=0.1, \mathrm{MeOH})$.

(S)-2-(2'-Hydroxyphenyl)-4-methoxycarbonyl-4,5-dihydrothiazole (7e). Colorless oil. $[\alpha]_{\mathrm{D}}^{20}+13.5^{\circ}(c=0.1$, $\mathrm{MeOH})[3]$.

(S)-2-(2'-Fluorophenyl)-4-methoxycarbonyl-4,5-dihydrothiazole (8e). White solid. m.p. 70-72 ${ }^{\circ} \mathrm{C} .{ }^{1} \mathrm{H}-\mathrm{NMR}$ $\left(\mathrm{CDCl}_{3}\right) \delta 7.95-7.92(\mathrm{~m}, 1 \mathrm{H}), 7.47-7.43(\mathrm{~m}, 1 \mathrm{H}), 7.21-7.11(\mathrm{~m}, 2 \mathrm{H}), 5.26(\mathrm{t}, J=9.5 \mathrm{~Hz}, 1 \mathrm{H}), 3.84(\mathrm{~s}, 3 \mathrm{H})$, 3.74-3.62 (m, 2H) ${ }^{13} \mathrm{C}-\mathrm{NMR}\left(\mathrm{CDCl}_{3}\right) \delta 171.2,166.0(\mathrm{~d}, J=5.04 \mathrm{~Hz}), 160.6,(\mathrm{~d}, J=255.78 \mathrm{~Hz}), 133.0(\mathrm{~d}$, $J=10.89 \mathrm{~Hz}), 130.7(\mathrm{~d}, J=2.52 \mathrm{~Hz}), 124.1(\mathrm{~d}, J=3.78 \mathrm{~Hz}), 120.7(\mathrm{~d}, J=11.43 \mathrm{~Hz}), 116.3(\mathrm{~d}, J=22.68 \mathrm{~Hz})$, 52.8, 40.1, 35.4. ESI-MS $m / z$ : Calcd for $\mathrm{C}_{11} \mathrm{H}_{10} \mathrm{FNO}_{2} \mathrm{~S}: 240.04[\mathrm{M}+\mathrm{H}]^{+}$; found: 240.12 . $[\alpha]_{\mathrm{D}}^{20}+14.4^{\circ}$ $(c=0.1, \mathrm{MeOH})$.

(S)-2-(2'-Chlorophenyl)-4-methoxycarbonyl-4,5-dihydrothiazole (9e). Yellow oil. ${ }^{1} \mathrm{H}-\mathrm{NMR}\left(\mathrm{CDCl}_{3}\right) \delta 7.66$ $(\mathrm{d}, J=7.6 \mathrm{~Hz}, 1 \mathrm{H}), 7.44-7.42(\mathrm{~m}, 1 \mathrm{H}), 7.37-7.28(\mathrm{~m}, 2 \mathrm{H}), 5.31(\mathrm{t}, J=9.5 \mathrm{~Hz}, 1 \mathrm{H}), 3.85(\mathrm{~s}, 3 \mathrm{H}), 3.79$ $(\mathrm{dd}, J=9.5,11.0 \mathrm{~Hz}, 1 \mathrm{H}), 3.69(\mathrm{t}, J=10.4 \mathrm{~Hz}, 1 \mathrm{H}) .{ }^{13} \mathrm{C}-\mathrm{NMR}\left(\mathrm{CDCl}_{3}\right) \delta 171.0,169.0,132.6,132.3$, 131.3, 130.7, 130.4, 126.7, 78.0, 52.8, 36.4. ESI-MS $m / z$ : Calcd for $\mathrm{C}_{11} \mathrm{H}_{10} \mathrm{ClNO}_{2} \mathrm{~S}: 256.01: 258.01=3: 1$ $[\mathrm{M}+\mathrm{H}]^{+}$; found: $256.27: 258.19=3: 1 .[\alpha]_{\mathrm{D}}^{20}+32.4^{\circ}(c=0.1, \mathrm{MeOH})$.

(S)-2-(2'-Bromophenyl)-4-methoxycarbonyl-4,5-dihydrothiazole (10e). Yellow oil. ${ }^{1} \mathrm{H}-\mathrm{NMR}\left(\mathrm{CDCl}_{3}\right) \delta$ 7.64-7.62 (m, 1H), 7.65-7.55 (m, 1H), 7.37-7.29 (m, 2H), 5.35-5.31 (m, $1 \mathrm{H}), 3.86-3.84(\mathrm{~m}, 3 \mathrm{H}), 3.81-3.69$ (m, 2H). ${ }^{13} \mathrm{C}-\mathrm{NMR}\left(\mathrm{CDCl}_{3}\right) \delta 175.5,170.9,170.2,134.5,133.6,131.4,130.6,127.2,121.3,78.3,52.8,36.5$. ESI-MS $m / z$ : Calcd for $\mathrm{C}_{11} \mathrm{H}_{10} \mathrm{BrNO}_{2} \mathrm{~S}: 299.96: 301.96=1: 1[\mathrm{M}+\mathrm{H}]^{+}$; found: 299.88:301.76 = 1:1. $[\alpha]_{\mathrm{D}}^{20}+22.0^{\circ}(c=0.1, \mathrm{MeOH})$.

(R)-2-Phenyl-4-methoxycarbonyl-4,5-dihydrothiazole (1e'). White powder. m.p. $60-62{ }^{\circ} \mathrm{C} .{ }^{1} \mathrm{H}-\mathrm{NMR}$ $\left(\mathrm{CDCl}_{3}\right) \delta 7.87(\mathrm{~d}, J=7.3 \mathrm{~Hz}, 2 \mathrm{H}), 7.48(\mathrm{t}, J=7.4 \mathrm{~Hz}, 1 \mathrm{H}), 7.41(\mathrm{t}, J=7.6 \mathrm{~Hz}, 2 \mathrm{H}), 5.30(\mathrm{t}, J=9.1 \mathrm{~Hz}, 1 \mathrm{H})$, $3.84(\mathrm{~s}, 3 \mathrm{H}), 3.73(\mathrm{dd}, J=8.8,11.0 \mathrm{~Hz}, 1 \mathrm{H}), 3.66-3.62(\mathrm{~m}, 1 \mathrm{H}) .{ }^{13} \mathrm{C}-\mathrm{NMR}\left(\mathrm{CDCl}_{3}\right) \delta 171.3,170.9,132.6$, 131.6, $128.6 \times 2,128.5 \times 2,78.5,52.7,35.3$. ESI-MS $m / z$ : Calcd for $\mathrm{C}_{11} \mathrm{H}_{11} \mathrm{NO}_{2} \mathrm{~S}: 222.05[\mathrm{M}+\mathrm{H}]^{+}$; found: $222.24 .[\alpha]_{\mathrm{D}}^{20}-129.0^{\circ}(c=0.1, \mathrm{MeOH})$.

(R)-2-(4'-Hydroxyphenyl)-4-methoxycarbonyl-4,5-dihydrothiazole (2e'). White powder. m.p. $166-168{ }^{\circ} \mathrm{C}$. ${ }^{1} \mathrm{H}-\mathrm{NMR}\left(\mathrm{CDCl}_{3}\right)$ 8 7.70-7.69 (m, 2H), 6.78-6.76 (m, 2H), $5.28(\mathrm{t}, J=9.0 \mathrm{~Hz}, 1 \mathrm{H}), 3.79(\mathrm{~s}, 3 \mathrm{H}), 3.72-3.62$ $(\mathrm{m}, 2 \mathrm{H}) .{ }^{13} \mathrm{C}-\mathrm{NMR}\left(\mathrm{CDCl}_{3}\right) \delta 172.1,171.5,159.7,130.6 \times 2,124.4,115.5 \times 2,77.6,52.8,35.3$. ESI-MS $m / z$ : Calcd for $\mathrm{C}_{11} \mathrm{H}_{11} \mathrm{NO}_{3} \mathrm{~S}$ : $238.05[\mathrm{M}+\mathrm{H}]^{+}$; found: 238.05. $[\alpha]_{\mathrm{D}}^{20}-109.6^{\circ}(c=0.1, \mathrm{MeOH})$.

(R)-2-(4'-Fluorophenyl)-4-methoxycarbonyl-4,5-dihydrothiazole (3e'). Yellow oil. ${ }^{1} \mathrm{H}-\mathrm{NMR}\left(\mathrm{CDCl}_{3}\right) \delta$ 7.89-7.86 (m, 2H), $7.10(\mathrm{t}, J=8.5 \mathrm{~Hz}, 2 \mathrm{H}), 5.28(\mathrm{t}, J=9.1 \mathrm{~Hz}, 1 \mathrm{H}), 3.84(\mathrm{~s}, 3 \mathrm{H}), 3.75-3.63(\mathrm{~m}, 2 \mathrm{H})$ ${ }^{13} \mathrm{C}-\mathrm{NMR}\left(\mathrm{CDCl}_{3}\right) \delta 171.2,169.6,164.8(\mathrm{~d}, J=252 \mathrm{~Hz}), 130.8,130.7,128.9,115.7,115.5,78.4,52.8,35.6$. ESI-MS $m / z$ : Calcd for $\mathrm{C}_{11} \mathrm{H}_{10} \mathrm{FNO}_{2} \mathrm{~S}: 240.04[\mathrm{M}+\mathrm{H}]^{+}$; found: $240.18 .[\alpha]_{\mathrm{D}}^{20}-57.8^{\circ}(c=0.1, \mathrm{MeOH})$.

(R)-2-(4'-Bromophenyl)-4-methoxycarbonyl-4,5-dihydrothiazole (4e'). White solid. m.p. $74-76{ }^{\circ} \mathrm{C}$. ${ }^{1} \mathrm{H}-\mathrm{NMR}\left(\mathrm{CDCl}_{3}\right) \delta 7.75-7.73(\mathrm{~m}, J=8.2 \mathrm{~Hz}, 2 \mathrm{H}), 7.57-7.55(\mathrm{~m}, J=8.2 \mathrm{~Hz}, 2 \mathrm{H}), 5.28(\mathrm{t}, J=9.1 \mathrm{~Hz}$, $1 \mathrm{H}), 3.85(\mathrm{~s}, 3 \mathrm{H}), 3.76-3.72(\mathrm{~m}, 1 \mathrm{H}), 3.68-3.64(\mathrm{~m}, 1 \mathrm{H}) .{ }^{13} \mathrm{C}-\mathrm{NMR}\left(\mathrm{CDCl}_{3}\right) \delta 171.2,170.0,131.8 \times 2$, 131.6, $130.1 \times 2,126.4,78.5,52.9$, 35.7. ESI-MS $m / z$ : Calcd for $\mathrm{C}_{11} \mathrm{H}_{10} \mathrm{BrNO}_{2} \mathrm{~S}: 299.96: 301.96=1: 1$ $[\mathrm{M}+\mathrm{H}]^{+}$; found: $299.79: 301.86=1: 1 .[\alpha]_{\mathrm{D}}^{20}-7.6^{\circ}(c=0.1, \mathrm{MeOH})$.

(R)-2-(3'-Hydroxyphenyl)-4-methoxycarbonyl-4,5-dihydrothiazole (5e'). Colourless oil. ${ }^{1} \mathrm{H}-\mathrm{NMR}\left(\mathrm{CDCl}_{3}\right)$ $\delta 7.38(\mathrm{~s}, 1 \mathrm{H}), 7.32(\mathrm{~d}, J=7.6 \mathrm{~Hz}, 1 \mathrm{H}), 7.23(\mathrm{t}, J=7.9 \mathrm{~Hz}, 1 \mathrm{H}), 6.98-6.96(\mathrm{~m}, 1 \mathrm{H}), 5.29(\mathrm{t}, J=9.1 \mathrm{~Hz}, 1 \mathrm{H})$, $3.81(\mathrm{~s}, 3 \mathrm{H}), 3.72-3.62(\mathrm{~m}, 2 \mathrm{H}) .{ }^{13} \mathrm{C}-\mathrm{NMR}\left(\mathrm{CDCl}_{3}\right) \delta 172.2,171.3,156.2,133.5,129.8,121.0,119.4,114.8$, 
77.9, 52.9, 35.2. ESI-MS $m / z$ : Calcd for $\mathrm{C}_{11} \mathrm{H}_{11} \mathrm{NO}_{3} \mathrm{~S}: 238.05[\mathrm{M}+\mathrm{H}]^{+}$; found: $238.24 .[\alpha]_{\mathrm{D}}^{20}-50.2^{\circ}$ $(c=0.1, \mathrm{MeOH})$.

(R)-2-(3'-Methylphenyl)-4-methoxycarbonyl-4,5-dihydrothiazole (6 $\left.\mathbf{e}^{\prime}\right)$. Colourless oil. ${ }^{1} \mathrm{H}-\mathrm{NMR}\left(\mathrm{CDCl}_{3}\right) \delta$ $7.72(\mathrm{~s}, 1 \mathrm{H}), 7.65-7.64(\mathrm{~m}, 1 \mathrm{H}), 7.30(\mathrm{~d}, J=4.7 \mathrm{~Hz}, 2 \mathrm{H}), 5.29(\mathrm{t}, J=9.1 \mathrm{~Hz}, 1 \mathrm{H}), 3.84(\mathrm{~s}, 3 \mathrm{H}), 3.74-3.61$ $(\mathrm{m}, 2 \mathrm{H}), 2.39(\mathrm{~s}, 3 \mathrm{H}) .{ }^{13} \mathrm{C}-\mathrm{NMR}\left(\mathrm{CDCl}_{3}\right) \delta 171.3,171.2,138.3,132.5,132.5,128.9,128.4,125.9,78.4$, 52.7, 35.3, 21.2. ESI-MS $m / z$ : Calcd for $\mathrm{C}_{12} \mathrm{H}_{13} \mathrm{NO}_{2} \mathrm{~S}: 236.07[\mathrm{M}+\mathrm{H}]^{+}$; found: $236.16 .[\alpha]_{\mathrm{D}}^{20}-71.7^{\circ}$ $(c=0.1, \mathrm{MeOH})$.

(R)-2-(2'-Hydroxyphenyl)-4-methoxycarbonyl-4,5-dihydrothiazole $\left(7 \mathbf{e}^{\prime}\right)$. Colorless oil. $[\alpha]_{\mathrm{D}}^{20}-13.9^{\circ}(c=0.1$, $\mathrm{MeOH})[3]$.

(R)-2-(2'-Fluorophenyl)-4-methoxycarbonyl-4,5-dihydrothiazole (8e'). White solid. m.p. $70-72{ }^{\circ} \mathrm{C}$. ${ }^{1} \mathrm{H}-\mathrm{NMR}\left(\mathrm{CDCl}_{3}\right)$ 8 7.95-7.92 (m, 1H), 7.47-7.42 (m, 1H), 7.20-7.11 (m, 2H), $5.25(\mathrm{t}, J=9.3 \mathrm{~Hz}, 1 \mathrm{H}), 3.84$ $(\mathrm{s}, 3 \mathrm{H}), 3.74-3.62(\mathrm{~m}, 2 \mathrm{H}) .{ }^{13} \mathrm{C}-\mathrm{NMR}\left(\mathrm{CDCl}_{3}\right) \delta 171.2,165.9(\mathrm{~d}, J=5.04 \mathrm{~Hz}), 160.6(\mathrm{~d}, J=255.78 \mathrm{~Hz})$, $133.0(\mathrm{~d}, J=8.82 \mathrm{~Hz}), 130.7(\mathrm{~d}, J=2.52 \mathrm{~Hz}), 124.1(\mathrm{~d}, J=2.52 \mathrm{~Hz}), 120.7(\mathrm{~d}, J=10.08 \mathrm{~Hz}), 116.3(\mathrm{~d}$, $J=22.68 \mathrm{~Hz}), 77.2,52.8,35.3(\mathrm{~d}, J=3.78 \mathrm{~Hz})$. ESI-MS $m / z$ : Calcd for $\mathrm{C}_{11} \mathrm{H}_{10} \mathrm{FNO}_{2} \mathrm{~S}: 240.04[\mathrm{M}+\mathrm{H}]^{+}$; found: $240.25 .[\alpha]_{\mathrm{D}}^{20}-14.4^{\circ}(c=0.1, \mathrm{MeOH})$.

(R)-2-(2'-Chlorophenyl)-4-methoxycarbonyl-4,5-dihydrothiazole (9e'). Yellow oil. ${ }^{1} \mathrm{H}-\mathrm{NMR}\left(\mathrm{CDCl}_{3}\right) \delta 7.65$ $(\mathrm{dd}, J=1.6,7.6 \mathrm{~Hz}, 1 \mathrm{H}), 7.44-7.42(\mathrm{~m}, 1 \mathrm{H}), 7.37-7.29(\mathrm{~m}, 2 \mathrm{H}), 5.30(\mathrm{t}, J=9.3 \mathrm{~Hz}, 1 \mathrm{H}), 3.85(\mathrm{~s}, 3 \mathrm{H}), 3.79$ $(\mathrm{dd}, J=9.1,11.0 \mathrm{~Hz}, 1 \mathrm{H}), 3.69(\mathrm{dd}, J=9.6,11.2 \mathrm{~Hz}, 1 \mathrm{H}) .{ }^{13} \mathrm{C}-\mathrm{NMR}\left(\mathrm{CDCl}_{3}\right) \delta 171.0,169.0,132.6,132.3$, 131.3, 130.7, 130.4, 126.7, 78.0, 52.8, 36.3. ESI-MS $m / z$ : Calcd for $\mathrm{C}_{11} \mathrm{H}_{10} \mathrm{ClNO}_{2} \mathrm{~S}: 256.01: 258.01=3: 1$ $[\mathrm{M}+\mathrm{H}]^{+}$; found: $256.12: 258.37=3: 1 .[\alpha]_{\mathrm{D}}^{20}-32.4^{\circ}(c=0.1, \mathrm{MeOH})$.

(R)-2-(2'-Bromophenyl)-4-methoxycarbonyl-4,5-dihydrothiazole (10e'). Yellow oil. ${ }^{1} \mathrm{H}-\mathrm{NMR}\left(\mathrm{CDCl}_{3}\right) \delta$ 7.64-7.54 (m, 2H), 7.37-7.24 (m, 2H), 5.35-5.29 (m, 1H), $3.85(\mathrm{~s}, 3 \mathrm{H}), 3.83-3.67(\mathrm{~m}, 2 \mathrm{H}) .{ }^{13} \mathrm{C}-\mathrm{NMR}$ $\left(\mathrm{CDCl}_{3}\right) \delta 170.9,170.1,134.5,133.6,131.4,130.6,127.2,121.3,78.2,52.8,36.5$. ESI-MS $m / z$ : Calcd for $\mathrm{C}_{11} \mathrm{H}_{10} \mathrm{BrNO}_{2} \mathrm{~S}: 299.96: 301.96=1: 1[\mathrm{M}+\mathrm{H}]^{+}$; found: 299.92:301.76 $=1: 1 .[\alpha]_{\mathrm{D}}^{20}-22.0^{\circ}(c=0.1, \mathrm{MeOH})$.

\subsubsection{Synthesis of $\mathbf{1 h}-\mathbf{1 0 h}$ and $\mathbf{1} \mathrm{h}^{\prime}-\mathbf{1 0 \mathrm { h } ^ { \prime }}$}

$\mathrm{NaBH}_{4}(52.8 \mathrm{mg}, 1.1 \mathrm{mmol})$ was added slowly in parts to a stirred solution of $\mathbf{1 e}-\mathbf{1 0 e}(1 \mathrm{mmol})$ in $\mathrm{EtOH}(10 \mathrm{~mL})$. After $1 \mathrm{~h}$, the reaction was complete (checked by TLC). Ethyl acetate was added, and then the mixture was washed with saturated aq. $\mathrm{NaHCO}_{3}(2 \times 5 \mathrm{~mL}), \mathrm{H}_{2} \mathrm{O}(2 \times 5 \mathrm{~mL})$, saturated aq. $\mathrm{NaCl}(2 \times 5 \mathrm{~mL})$, and dried with anhydrous $\mathrm{Na}_{2} \mathrm{SO}_{4}$. The mixture was concentrated under vacuum, and the crude product was chromatographed on silica gel to obtain the products $\mathbf{1 e}-\mathbf{1 0 e}$ and $\mathbf{1} \mathbf{e}^{\prime}-\mathbf{1 0} \mathbf{e}^{\prime}$. The yields of $\mathbf{1 h}-\mathbf{1 0 h}$ and $\mathbf{1} \mathbf{h}^{\prime}-\mathbf{1 0 \mathbf { h } ^ { \prime }}$ were from $76 \%$ to $89 \%$.

(S)-2-Phenyl-4-hydroxymethyly-4,5-dihydrothiazole (1h). Yellow solid. m.p. 76-78 ${ }^{\circ} \mathrm{C} .{ }^{1} \mathrm{H}-\mathrm{NMR}\left(\mathrm{CDCl}_{3}\right)$ $\delta 7.81(\mathrm{~d}, J=7.6 \mathrm{~Hz}, 2 \mathrm{H}), 7.48-7.39(\mathrm{~m}, 3 \mathrm{H}), 4.83-4.77(\mathrm{~m}, 1 \mathrm{H}), 4.02(\mathrm{dd}, J=4.6,11.2 \mathrm{~Hz}, 1 \mathrm{H}), 3.80$ $(\mathrm{dd}, J=5.7,11.3 \mathrm{~Hz}, 1 \mathrm{H}), 3.46-3.42(\mathrm{~m}, 1 \mathrm{H}), 3.33-3.29(\mathrm{~m}, 1 \mathrm{H}) .{ }^{13} \mathrm{C}-\mathrm{NMR}\left(\mathrm{CDCl}_{3}\right) \delta 169.7,132.9,131.4$, $128.5 \times 2,128.4 \times 2,79.3,64.5,34.4$. ESI-MS $m / z$ : Calcd for $\mathrm{C}_{10} \mathrm{H}_{11} \mathrm{NOS}: 194.06[\mathrm{M}+\mathrm{H}]^{+}$; found: 194.22. $[\alpha]_{\mathrm{D}}^{20}+30.7^{\circ}(c=0.1, \mathrm{MeOH})$.

(S)-2-(4'-Hydroxyphenyl)-4-hydroxymethyl-4,5-dihydrothiazole (2h). White solid. m.p. 196-198 ${ }^{\circ} \mathrm{C}$. ${ }^{1} \mathrm{H}-\mathrm{NMR}\left(\mathrm{DMSO}-d_{6}\right) \delta 10.06(\mathrm{~s}, 1 \mathrm{H}), 7.59(\mathrm{~d}, J=8.5 \mathrm{~Hz}, 2 \mathrm{H}), 6.81(\mathrm{~d}, J=8.5 \mathrm{~Hz}, 2 \mathrm{H}), 4.91(\mathrm{t}, J=5.4 \mathrm{~Hz}$, $1 \mathrm{H}), 4.66-4.60(\mathrm{~m}, 1 \mathrm{H}), 3.68-3.64(\mathrm{~m}, 1 \mathrm{H}), 3.50-3.40(\mathrm{~m}, 2 \mathrm{H}), 3.30-3.27(\mathrm{~m}, 1 \mathrm{H}) .{ }^{13} \mathrm{C}-\mathrm{NMR}$ (DMSO- $\left.d_{6}\right)$ $\delta 165.3,160.2,129.9 \times 2,124.0,115.3 \times 2,79.3,62.3,34.5$. ESI-MS $m / z$ : Calcd for $\mathrm{C}_{10} \mathrm{H}_{11} \mathrm{NO}_{2} \mathrm{~S}: 210.05$ $[\mathrm{M}+\mathrm{H}]^{+}$; found: $210.23 .[\alpha]_{\mathrm{D}}^{20}+124.0^{\circ}(c=0.1, \mathrm{MeOH})$.

(S)-2-(4'-Fluorophenyl)-4-hydroxymethyly-4,5-dihydrothiazole (3h). White solid. m.p. $60-62{ }^{\circ} \mathrm{C} .{ }^{1} \mathrm{H}-\mathrm{NMR}$ $\left(\mathrm{CDCl}_{3}\right) \delta 7.79-7.76(\mathrm{~m}, 2 \mathrm{H}), 7.07(\mathrm{t}, J=10 \mathrm{~Hz}, 2 \mathrm{H}), 4.79-4.74(\mathrm{~m}, 1 \mathrm{H}), 4.03(\mathrm{dd}, J=4.4,11.3 \mathrm{~Hz}, 1 \mathrm{H})$, $3.78(\mathrm{dd}, J=5.5,11.2 \mathrm{~Hz}, 1 \mathrm{H}), 3.43(\mathrm{dd}, J=9.0,10.9 \mathrm{~Hz}, 1 \mathrm{H}), 3.35-3.31(\mathrm{~m}, 1 \mathrm{H}) .{ }^{13} \mathrm{C}-\mathrm{NMR}\left(\mathrm{CDCl}_{3}\right)$ $\delta 168.4,164.6(\mathrm{~d}, J=252 \mathrm{~Hz}) 130.5,130.4,129.1,115.6,115.4,79.3,64.3,34.6$. ESI-MS $m / z$ : Calcd for $\mathrm{C}_{10} \mathrm{H}_{10}$ FNOS: $212.05[\mathrm{M}+\mathrm{H}]^{+}$; found: 212.31. $[\alpha]_{\mathrm{D}}^{20}+10.9^{\circ}(c=0.1, \mathrm{MeOH})$. 
(S)-2-(4'-Bromophenyl)-4-hydroxymethyl-4,5-dihydrothiazole (4h). White solid. m.p. $96-98{ }^{\circ} \mathrm{C} .{ }^{1} \mathrm{H}-\mathrm{NMR}$ $\left(\mathrm{CDCl}_{3}\right) \delta 7.67-7.65(\mathrm{~m}, 2 \mathrm{H}), 7.54-7.52(\mathrm{~m}, 2 \mathrm{H}), 4.80-4.75(\mathrm{~m}, 1 \mathrm{H}), 4.03(\mathrm{dd}, J=4.7,11.3 \mathrm{~Hz}$, $1 \mathrm{H}), 3.79(\mathrm{dd}, J=5.7,11.3 \mathrm{~Hz}, 1 \mathrm{H}), 3.46(\mathrm{dd}, J=8.8,10.7 \mathrm{~Hz}, 1 \mathrm{H}), 3.33(\mathrm{dd}, J=9.3$, $10.9 \mathrm{~Hz}, 1 \mathrm{H}) .{ }^{13} \mathrm{C}-\mathrm{NMR}\left(\mathrm{CDCl}_{3}\right) \delta 168.7,131.8,131.7 \times 2,129.8 \times 2,126.0,79.4,64.4,34.6$. ESI-MS $m / z$ : Calcd for $\mathrm{C}_{10} \mathrm{H}_{10}$ BrNOS: 271.97:273.97 $=1: 1[\mathrm{M}+\mathrm{H}]^{+}$; found: $272.16: 274.04=1: 1$. $[\alpha]_{\mathrm{D}}^{20}+26.6^{\circ}(c=0.1, \mathrm{MeOH})$.

(S)-2-(3'-Hydroxyphenyl)-4-hydroxymethyl-4,5-dihydrothiazole (5h). White solid. m.p. $118-120{ }^{\circ} \mathrm{C}$. ${ }^{1} \mathrm{H}-\mathrm{NMR}\left(\mathrm{CD}_{3} \mathrm{OD}\right) \delta 7.27-7.23(\mathrm{~m}, 3 \mathrm{H}), 6.98-6.96(\mathrm{~m}, 1 \mathrm{H}), 4.78-4.73(\mathrm{~m}, 1 \mathrm{H}), 4.04(\mathrm{~s}, 2 \mathrm{H}), 3.85-3.78$ $(\mathrm{m}, 2 \mathrm{H}) .{ }^{13} \mathrm{C}-\mathrm{NMR}\left(\mathrm{CD}_{3} \mathrm{OD}\right) \delta 171.1,156.8,133.6,129.5,119.7,118.7,114.2,78.5,63.1,34.2$. ESI-MS $m / z$ : Calcd for $\mathrm{C}_{10} \mathrm{H}_{11} \mathrm{NO}_{2} \mathrm{~S}: 210.05[\mathrm{M}+\mathrm{H}]^{+}$; found: 210.27. $[\alpha]_{\mathrm{D}}^{20}+178.2^{\circ}(c=0.1, \mathrm{MeOH})$.

(S)-2-(3'-Methylphenyl)-4-hydroxymethyl-4,5-dihydrothiazole (6h). Yellow oil. ${ }^{1} \mathrm{H}-\mathrm{NMR}\left(\mathrm{CDCl}_{3}\right) \delta$ 7.62-7.57 (m, 2H), 7.28-7.27 (m, 2H), 4.81-4.75 (m, 1H), $4.02(\mathrm{dd}, J=4.7,11.0 \mathrm{~Hz}, 1 \mathrm{H}), 3.79(\mathrm{dd}, J=5.5$, $11.2 \mathrm{~Hz}, 1 \mathrm{H}), 3.42(\mathrm{dd}, J=8.8,10.7 \mathrm{~Hz}, 1 \mathrm{H}), 3.31(\mathrm{dd}, J=9.5,10.7 \mathrm{~Hz}, 1 \mathrm{H}), 2.38(\mathrm{~s}, 3 \mathrm{H}) .{ }^{13} \mathrm{C}-\mathrm{NMR}$ $\left(\mathrm{CDCl}_{3}\right) \delta 169.9,138.2,132.8,132.1,128.8,128.3,125.6,79.3,64.4,34.3,21.2$. ESI-MS $m / z$ : Calcd for $\mathrm{C}_{11} \mathrm{H}_{13} \mathrm{NOS}: 208.07[\mathrm{M}+\mathrm{H}]^{+}$; found: 208.32. $[\alpha]_{\mathrm{D}}^{20}+7.6^{\circ}(c=0.1, \mathrm{MeOH})$.

(S)-2-(2'-Hydroxyphenyl)-4-hydroxymethyl-4,5-dihydrothiazole (7h). White solid. m.p. $43-45{ }^{\circ} \mathrm{C}$. $[\alpha]_{\mathrm{D}}^{20}+16.5^{\circ}(c=0.1, \mathrm{MeOH})[3]$.

(S)-2-(2'-Fluorophenyl)-4-hydroxymethyl-4,5-dihydrothiazole (8h). White solid. m.p. 78-80 ${ }^{\circ} \mathrm{C} .{ }^{1} \mathrm{H}-\mathrm{NMR}$ $\left(\mathrm{CDCl}_{3}\right) \delta 7.86-7.82(\mathrm{~m}, 1 \mathrm{H}), 7.46-7.41(\mathrm{~m}, 1 \mathrm{H}), 7.20-7.11(\mathrm{~m}, 2 \mathrm{H}), 4.81-4.75(\mathrm{~m}, 1 \mathrm{H}), 4.00(\mathrm{dd}, J=4.9$, $11.2 \mathrm{~Hz}, 1 \mathrm{H}), 3.80(\mathrm{dd}, J=5.7,11.3 \mathrm{~Hz}, 1 \mathrm{H}), 3.44(\mathrm{dd}, J=9.1,10.7 \mathrm{~Hz}, 1 \mathrm{H}), 3.30(\mathrm{dd}, J=9.1,10.7 \mathrm{~Hz}$, 1H). ${ }^{13} \mathrm{C}-\mathrm{NMR}\left(\mathrm{CDCl}_{3}\right) \delta 164.6(\mathrm{~d}, J=5.04 \mathrm{~Hz}), 160.3(\mathrm{~d}, J=255.78 \mathrm{~Hz}), 132.6(\mathrm{~d}, J=8.82 \mathrm{~Hz}), 130.5(\mathrm{~d}$, $J=1.26 \mathrm{~Hz}), 124.1(\mathrm{~d}, J=3.78 \mathrm{~Hz}), 121.1(\mathrm{~d}, J=10.1 \mathrm{~Hz}), 116.4(\mathrm{~d}, J=25.2 \mathrm{~Hz}), 78.4,64.4,34.4$. ESI-MS $m / z$ : Calcd for $\mathrm{C}_{10} \mathrm{H}_{10} \mathrm{FNOS}: 212.05[\mathrm{M}+\mathrm{H}]^{+}$; found: 212.41. $[\alpha]_{\mathrm{D}}^{20}+25.9^{\circ}(c=0.1, \mathrm{MeOH})$.

(S)-2-(2'-Chlorophenyl)-4-hydroxymethyl-4,5-dihydrothiazole (9h). Yellow oil. ${ }^{1} \mathrm{H}-\mathrm{NMR}\left(\mathrm{CDCl}_{3}\right) \delta 7.57$ $(\mathrm{dd}, J=1.6,7.6 \mathrm{~Hz}, 1 \mathrm{H}), 7.44-7.42(\mathrm{~m}, 1 \mathrm{H}), 7.36-7.29(\mathrm{~m}, 2 \mathrm{H}), 4.85-4.80(\mathrm{~m}, 1 \mathrm{H}), 3.95(\mathrm{dd}, J=4.9$, $11.2 \mathrm{~Hz}, 1 \mathrm{H}), 3.78(\mathrm{dd}, J=5.5,11.2 \mathrm{~Hz}, 1 \mathrm{H}), 3.48(\mathrm{dd}, J=9.1,10.7 \mathrm{~Hz}, 1 \mathrm{H}), 3.36(\mathrm{dd}, J=8.7,10.9 \mathrm{~Hz}$, 1H). ${ }^{13} \mathrm{C}-\mathrm{NMR}\left(\mathrm{CDCl}_{3}\right) \delta 167.5,132.7,132.1,131.1,130.4,130.3,126.7,79.2,64.2,35.5$. ESI-MS $\mathrm{m} / z$ : Calcd for $\mathrm{C}_{10} \mathrm{H}_{10} \mathrm{ClNOS}: 228.02: 230.02=3: 1[\mathrm{M}+\mathrm{H}]^{+}$; found: $228.21: 230.37=3: 1 . \quad[\alpha]_{\mathrm{D}}^{20}+19.4^{\circ}$ $(c=0.1, \mathrm{MeOH})$.

(S)-2-(2'-Bromophenyl)-4-hydroxymethyl-4,5-dihydrothiazole (10h). Yellow solid. m.p. 54-56 ${ }^{\circ} \mathrm{C}$. ${ }^{1} \mathrm{H}-\mathrm{NMR}\left(\mathrm{CDCl}_{3}\right) \delta 7.64(\mathrm{~d}, J=7.9 \mathrm{~Hz}, 1 \mathrm{H}), 7.51(\mathrm{~d}, J=7.6 \mathrm{~Hz}, 1 \mathrm{H}), 7.37-7.29(\mathrm{~m}, 2 \mathrm{H}), 4.91-4.86$ $(\mathrm{m}, 1 \mathrm{H}), 4.04-4.01(\mathrm{~m}, 1 \mathrm{H}), 3.81(\mathrm{dd}, J=5.5,11.2 \mathrm{~Hz}, 1 \mathrm{H}), 3.55-3.51(\mathrm{~m}, 1 \mathrm{H}), 3.42(\mathrm{dd}, J=8.8,10.7 \mathrm{~Hz}$, 1H). ${ }^{13} \mathrm{C}-\mathrm{NMR}\left(\mathrm{CDCl}_{3}\right) \delta 168.7,134.8,133.6,131.2,130.2,127.3,121.0,79.5,64.5,35.7$. ESI-MS $m / z$ : Calcd for $\mathrm{C}_{10} \mathrm{H}_{10} \mathrm{BrNOS} 271.97: 273.97=1: 1[\mathrm{M}+\mathrm{H}]^{+}$; found: $271.86: 273.91=1: 1 . \quad[\alpha]_{\mathrm{D}}^{20}+109.1^{\circ}$ $(c=0.1, \mathrm{MeOH})$.

(R)-2-Phenyl-4-hydroxymethyl-4,5-dihydrothiazole (1h'). Yellow solid. m.p. $76-78{ }^{\circ} \mathrm{C} .{ }^{1} \mathrm{H}-\mathrm{NMR}\left(\mathrm{CDCl}_{3}\right)$ $\delta 7.79(\mathrm{~d}, J=7.9 \mathrm{~Hz}, 2 \mathrm{H}), 7.47-7.37(\mathrm{~m}, 4 \mathrm{H}), 4.80-4.75(\mathrm{~m}, 1 \mathrm{H}), 4.01(\mathrm{dd}, J=4.7,11.0 \mathrm{~Hz}, 1 \mathrm{H}), 3.79$ $(\mathrm{dd}, J=5.5,11.2 \mathrm{~Hz}, 1 \mathrm{H}), 3.44-3.40(\mathrm{~m}, 1 \mathrm{H}), 3.33-3.29(\mathrm{~m}, 1 \mathrm{H}), 2.78$ (br. s, $1 \mathrm{H}) .{ }^{13} \mathrm{C}-\mathrm{NMR}\left(\mathrm{CDCl}_{3}\right) \delta$ $169.8,132.8,131.4,128.4 \times 2,128.3 \times 2,79.3,64.3,34.3$. ESI-MS $m / z$ : Calcd for $\mathrm{C}_{10} \mathrm{H}_{11} \mathrm{NO}_{2} \mathrm{~S}: 194.06$ $[\mathrm{M}+\mathrm{H}]^{+}$; found: 194.23. $[\alpha]_{\mathrm{D}}^{20}-30.6^{\circ}(c=0.1, \mathrm{MeOH})$.

(R)-2-(4'-Hydroxyphenyl)-4-hydroxymethyl-4,5-dihydrothiazole (2h'). White solid. m.p. 196-198 ${ }^{\circ} \mathrm{C}$. ${ }^{1} \mathrm{H}-\mathrm{NMR}$ (DMSO- $\left.d_{6}\right) \delta 10.12(\mathrm{~s}, 1 \mathrm{H}), 7.75-7.60(\mathrm{~m}, 2 \mathrm{H}), 6.95-6.80(\mathrm{~m}, 2 \mathrm{H}), 4.97(\mathrm{t}, J=5.7 \mathrm{~Hz}, 1 \mathrm{H})$, $4.72-4.66(\mathrm{~m}, 1 \mathrm{H}), 3.75-3.70(\mathrm{~m}, 1 \mathrm{H}), 3.56-3.51(\mathrm{~m}, 1 \mathrm{H}), 3.48(\mathrm{dd}, J=8.7,10.9 \mathrm{~Hz}, 1 \mathrm{H}), 3.35(\mathrm{dd}, J=7.4$, $10.9 \mathrm{~Hz}, 1 \mathrm{H}$ ). ${ }^{13} \mathrm{C}-\mathrm{NMR}$ (DMSO- $\left.d_{6}\right) \delta 165.3,160.2,129.8 \times 2,124.0,115.3 \times 2,79.3,62.3,34.5$. ESI-MS $m / z$ : Calcd for $\mathrm{C}_{11} \mathrm{H}_{11} \mathrm{NO}_{2} \mathrm{~S}: 210.05[\mathrm{M}+\mathrm{H}]^{+}$; found: 210.16. $[\alpha]_{\mathrm{D}}^{20}-123.9^{\circ}(c=0.1, \mathrm{MeOH})$. 
(R)-2-(4'-Fluorophenyl)-4-hydroxymethyl-4,5-dihydrothiazole $\left(3 \mathbf{h}^{\prime}\right)$. White solid. m.p. $60-62{ }^{\circ} \mathrm{C} .{ }^{1} \mathrm{H}-\mathrm{NMR}$ $\left(\mathrm{CDCl}_{3}\right) \delta 7.81(\mathrm{dd}, J=5.4,8.8 \mathrm{~Hz}, 2 \mathrm{H}), 7.08(\mathrm{t}, J=8.5 \mathrm{~Hz}, 2 \mathrm{H}), 4.81-4.75(\mathrm{~m}, 1 \mathrm{H}), 4.02(\mathrm{dd}, J=4.6$, $11.2 \mathrm{~Hz}, 1 \mathrm{H}), 3.79(\mathrm{dd}, J=5.7,11.0 \mathrm{~Hz}, 1 \mathrm{H}), 3.45(\mathrm{dd}, J=8.8,10.7 \mathrm{~Hz}, 1 \mathrm{H}), 3.34-3.30(\mathrm{~m}, 1 \mathrm{H}) .{ }^{13} \mathrm{C}-\mathrm{NMR}$ $\left(\mathrm{CDCl}_{3}\right) \delta 168.3,164.6(\mathrm{~d}, J=252 \mathrm{~Hz}), 130.5,130.5,129.2,115.6,115.5,79.3,64.5,34.7$. ESI-MS $m / z$ : Calcd for $\mathrm{C}_{10} \mathrm{H}_{10}$ FNOS: $212.05[\mathrm{M}+\mathrm{H}]^{+}$; found: 212.11. $[\alpha]_{\mathrm{D}}^{20}-10.9^{\circ}(c=0.1, \mathrm{MeOH})$.

(R)-2-(4'-Bromophenyl)-4-hydroxymethyl-4,5-dihydrothiazole $\left(4 \mathbf{h}^{\prime}\right)$. White solid. m.p. $96-98{ }^{\circ} \mathrm{C} .{ }^{1} \mathrm{H}-\mathrm{NMR}$ $\left(\mathrm{CDCl}_{3}\right) \delta 7.68-7.66(\mathrm{~m}, 2 \mathrm{H}), 7.55-7.53(\mathrm{~m}, 2 \mathrm{H}), 4.81-4.76(\mathrm{~m}, 1 \mathrm{H}), 4.03(\mathrm{dd}, J=4.7,11.0 \mathrm{~Hz}, 1 \mathrm{H})$, $3.79(\mathrm{dd}, J=5.7,11.3 \mathrm{~Hz}, 1 \mathrm{H}), 3.46(\mathrm{dd}, J=8.8,10.7 \mathrm{~Hz}, 1 \mathrm{H}), 3.33(\mathrm{dd}, J=9.3,10.9 \mathrm{~Hz}, 1 \mathrm{H})$. ${ }^{13} \mathrm{C}-\mathrm{NMR}\left(\mathrm{CDCl}_{3}\right) \delta 168.5,131.8,131.7 \times 2,129.8 \times 2,126.0,79.4,64.5,34.6$. ESI-MS $\mathrm{m} / \mathrm{z}$ : Calcd for $\mathrm{C}_{10} \mathrm{H}_{10}$ BrNOS: 271.97:273.97 = 1:1 $[\mathrm{M}+\mathrm{H}]^{+}$; found: $271.82: 273.77=1: 1 .[\alpha]_{\mathrm{D}}^{20}-26.6^{\circ}(c=0.1, \mathrm{MeOH})$.

(R)-2-(3'-Hydroxyphenyl)-4-hydroxymethyl-4,5-dihydrothiazole (5h'). White solid. m.p. $118-120{ }^{\circ} \mathrm{C}$. ${ }^{1} \mathrm{H}-\mathrm{NMR}\left(\mathrm{CDCl}_{3}\right) \delta 7.35$ (br. s, 1H), 7.27-7.24 (m, 2H), 6.97-6.96 (m, 1H), 4.75-4.74 (m, 1H), 3.82-3.80 $(\mathrm{m}, 2 \mathrm{H}), 3.62-3.61(\mathrm{~m}, 2 \mathrm{H}) .{ }^{13} \mathrm{C}-\mathrm{NMR}\left(\mathrm{CDCl}_{3}\right) \delta 171.3,156.8,133.6,129.6,120.0,118.9,114.0,78.5$, 63.3, 34.2. ESI-MS $m / z$ : Calcd for $\mathrm{C}_{10} \mathrm{H}_{11} \mathrm{NO}_{2} \mathrm{~S}: 210.05[\mathrm{M}+\mathrm{H}]^{+}$; found: 210.23 . $[\alpha]_{\mathrm{D}}^{20}-178.2^{\circ}$ $(c=0.1, \mathrm{MeOH})$.

(R)-2-(3'-Methylphenyl)-4-hydroxymethyl-4,5-dihydrothiazole $\left(\mathbf{6 h}^{\prime}\right)$. Yellow oil. ${ }^{1} \mathrm{H}-\mathrm{NMR}\left(\mathrm{CDCl}_{3}\right) \delta$ 7.61-7.56 (m, 2H), 7.29-7.26 (m, 2H), 4.79-4.74 (m, 1H), $4.01(\mathrm{dd}, J=4.7,11.3 \mathrm{~Hz}, 1 \mathrm{H}), 3.78(\mathrm{dd}, J=5.5$, $11.2 \mathrm{~Hz}, 1 \mathrm{H}), 3.41(\mathrm{dd}, J=8.8,10.7 \mathrm{~Hz}, 1 \mathrm{H}), 3.30(\mathrm{dd}, J=9.1,10.7 \mathrm{~Hz}, 1 \mathrm{H}), 2.37(\mathrm{~s}, 3 \mathrm{H}) .{ }^{13} \mathrm{C}-\mathrm{NMR}$ $\left(\mathrm{CDCl}_{3}\right) \delta 169.9,138.2,132.7,132.1,128.8,128.3,125.6,79.2,64.3,34.2,21.2$. ESI-MS $\mathrm{m} / z$ : Calcd for $\mathrm{C}_{11} \mathrm{H}_{13} \mathrm{NOS}: 208.07[\mathrm{M}+\mathrm{H}]^{+}$; found: 208.01. $[\alpha]_{\mathrm{D}}^{20}-7.6^{\circ}(c=0.1, \mathrm{MeOH})$.

(R)-2-(2'-Hydroxyphenyl)-4-hydroxymethyl-4,5-dihydrothiazole $\left(\mathbf{7 h}^{\prime}\right)$. White solid. m.p. $\quad 44-46{ }^{\circ} \mathrm{C}$. $[\alpha]_{\mathrm{D}}^{20}-16.1^{\circ}(c=0.1, \mathrm{MeOH})[3]$.

(R)-2-(2'-Fluorophenyl)-4-hydroxymethyl-4,5-dihydrothiazole $\left(\mathbf{8 h}^{\prime}\right)$. White solid. m.p. $78-80{ }^{\circ} \mathrm{C} .{ }^{1} \mathrm{H}-\mathrm{NMR}$ $\left(\mathrm{CDCl}_{3}\right) \delta 7.94-7.75(\mathrm{~m}, 1 \mathrm{H}), 7.57-7.34(\mathrm{~m}, 1 \mathrm{H}), 7.24-7.02(\mathrm{~m}, 2 \mathrm{H}), 4.86-4.71(\mathrm{~m}, 1 \mathrm{H}), 4.00(\mathrm{dd}, \mathrm{J}=4.7$, $11.3 \mathrm{~Hz}, 1 \mathrm{H}), 3.80(\mathrm{dd}, J=5.7,11.0 \mathrm{~Hz}, 1 \mathrm{H}), 3.44(\mathrm{dd}, J=9.0,10.9 \mathrm{~Hz}, 1 \mathrm{H}), 3.31(\mathrm{dd}, J=9.5,10.7 \mathrm{~Hz}$, 1H), 2.62 (br. s, $1 \mathrm{H}) .{ }^{13} \mathrm{C}-\mathrm{NMR}\left(\mathrm{CDCl}_{3}\right) \delta 164.6(\mathrm{~d}, J=5.04 \mathrm{~Hz}), 160.4,(\mathrm{~d}, J=255.78 \mathrm{~Hz}), 132.6(\mathrm{~d}$, $J=8.82 \mathrm{~Hz}), 130.5(\mathrm{~d}, J=2.52 \mathrm{~Hz}), 124.1(\mathrm{~d}, J=3.78 \mathrm{~Hz}), 121.1(\mathrm{~d}, J=11.34 \mathrm{~Hz}), 116.4(\mathrm{~d}, J=22.68 \mathrm{~Hz})$, 78.4, 64.4, $34.4(\mathrm{~d}, \mathrm{~J}=2.52 \mathrm{~Hz})$. ESI-MS $m / z$ : Calcd for $\mathrm{C}_{10} \mathrm{H}_{10} \mathrm{FNOS:} 212.05[\mathrm{M}+\mathrm{H}]^{+}$; found: 212.29 . $[\alpha]_{\mathrm{D}}^{20}-25.9^{\circ}(c=0.1, \mathrm{MeOH})$.

(R)-2-(2'-Chlorophenyl)-4-hydroxymethyl-4,5-dihydrothiazole $\left(\mathbf{9 h}^{\prime}\right) . \quad$ Yellow oil. ${ }^{1} \mathrm{H}-\mathrm{NMR}\left(\mathrm{CDCl}_{3}\right) \delta$ $7.58(\mathrm{~d}, J=7.6 \mathrm{~Hz}, 1 \mathrm{H}), 7.44(\mathrm{~d}, J=7.6 \mathrm{~Hz}, 1 \mathrm{H}), 7.36-7.28(\mathrm{~m}, 2 \mathrm{H}), 4.86-4.80(\mathrm{~m}, 1 \mathrm{H}), 3.96$ $(\mathrm{dd}, J=4.9,11.2 \mathrm{~Hz}, 1 \mathrm{H}), 3.81-3.77(\mathrm{~m}, 1 \mathrm{H}), 3.53-3.47(\mathrm{~m}, 1 \mathrm{H}), 3.41-3.35(\mathrm{~m}, 1 \mathrm{H}) .{ }^{13} \mathrm{C}-\mathrm{NMR}$ $\left(\mathrm{CDCl}_{3}\right) \delta 167.5,132.7,132.1,131.1,130.4,130.4,126.7,79.2,64.2,35.5$. ESI-MS $\mathrm{m} / \mathrm{z}$ : Calcd for $\mathrm{C}_{10} \mathrm{H}_{10} \mathrm{ClNOS}: 228.02: 230.02=3: 1[\mathrm{M}+\mathrm{H}]^{+}$; found: $228.16: 230.27=3: 1 .[\alpha]_{\mathrm{D}}^{20}-19.4^{\circ}(c=0.1, \mathrm{MeOH})$.

(R)-2-(2'-Bromophenyl)-4-hydroxymethyl-4,5-dihydrothiazole (10h'). Yellow solid. m.p. $54-56{ }^{\circ} \mathrm{C}$. ${ }^{1} \mathrm{H}-\mathrm{NMR}\left(\mathrm{CDCl}_{3}\right) \delta$ 7.69-7.63 (m, 1H), 7.55-7.50 (m, 1H), 7.36-7.28 (m, 1H), 4.90-4.85 (m, 1H), 4.03-3.95 (m, 1H), 3.83-3.76 (m, 1H), 3.55-3.51 (m, 1H), 3.46-3.39 (m, 1H). ${ }^{13} \mathrm{C}-\mathrm{NMR}\left(\mathrm{CDCl}_{3}\right) \delta$ 168.7, 133.6, 131.7, 131.2, 130.2, 129.8, 127.3, 79.4, 64.4, 35.6. ESI-MS $m / z$ : Calcd for $\mathrm{C}_{10} \mathrm{H}_{10} \mathrm{BrNOS}$ 271.97:273.97 = 1:1 $[\mathrm{M}+\mathrm{H}]^{+}$; found: $271.82: 273.79=1: 1 .[\alpha]_{\mathrm{D}}^{20}-109.1^{\circ}(c=0.1, \mathrm{MeOH})$.

\subsubsection{Synthesis of $\mathbf{1 a}-\mathbf{1 0} \mathbf{a}$ and $\mathbf{1} \mathbf{a}^{\prime}-\mathbf{1 0} \mathbf{a}^{\prime}$}

$10 \%$ sodium hydroxide solution was added slowly in parts to a stirred solution of $\mathbf{1 e - 1 0 e}$ and $\mathbf{1} \mathbf{e}^{\prime}-\mathbf{1 0} \mathbf{e}^{\prime}(1 \mathrm{mmol})$ in EtOH $(10 \mathrm{~mL})$. After $2 \mathrm{~h}$, the reaction was complete (checked by TLC). Purification of the crude reaction mixture by column chromatography on silica gel (PE/ EA) afforded the desired products and the yields were from $81 \%$ to $90 \%$.

(S)-2-Phenyl-4-carboxy-4,5-dihydrothiazole (1a). Yellow powder. m.p. $116-118{ }^{\circ} \mathrm{C} .{ }^{1} \mathrm{H}-\mathrm{NMR}\left(\mathrm{CDCl}_{3}\right) \delta$ $7.83(\mathrm{~d}, J=7.6 \mathrm{~Hz}, 2 \mathrm{H}), 7.48-7.45(\mathrm{~m}, 1 \mathrm{H}), 7.40-7.38(\mathrm{~m}, 2 \mathrm{H}), 5.26(\mathrm{t}, J=9.1 \mathrm{~Hz}, 1 \mathrm{H}), 3.72-3.64(\mathrm{~m}, 2 \mathrm{H})$. 
${ }^{13} \mathrm{C}-\mathrm{NMR}\left(\mathrm{CDCl}_{3}\right) \delta$ 172.6, 171.8, 132.4, 131.7, $128.9 \times 2,128.1 \times 2,78.1$, 35.1. ESI-MS $m / z$ : Calcd for $\mathrm{C}_{10} \mathrm{H}_{9} \mathrm{NO}_{2} \mathrm{~S}: 208.04[\mathrm{M}+\mathrm{H}]^{+}$; found: 208.25. $[\alpha]_{\mathrm{D}}^{20}+10.5^{\circ}(c=0.1, \mathrm{MeOH})$.

(S)-2-(4'-Hydroxyphenyl)-4-carboxy-4,5-dihydrothiazole (2a). White solid. m.p. $150-152{ }^{\circ} \mathrm{C} .[\alpha]_{\mathrm{D}}^{20}+12.5^{\circ}$ $(c=0.1, \mathrm{MeOH})[13]$.

(S)-2-(4'-Fluorophenyl)-4-carboxy-4,5-dihydrothiazole (3a). White solid. m.p. $120-122{ }^{\circ} \mathrm{C} .{ }^{1} \mathrm{H}-\mathrm{NMR}$ $\left(\mathrm{CDCl}_{3}\right) \delta 9.14$ (br. s, $\left.1 \mathrm{H}\right), 7.87(\mathrm{dd}, J=5.4,8.5 \mathrm{~Hz}, 2 \mathrm{H}), 7.12(\mathrm{t}, J=8.5 \mathrm{~Hz}, 2 \mathrm{H}), 5.38(\mathrm{t}, J=9.1 \mathrm{~Hz}, 1 \mathrm{H})$, 3.78-3.70 (m, 2H). ${ }^{13} \mathrm{C}-\mathrm{NMR}\left(\mathrm{CDCl}_{3}\right) \delta 173.6,172.0,165.1(\mathrm{~d}, J=252 \mathrm{~Hz}), 130.9,130.9,128.3,115.9$, 115.7, 77.6, 35.3. ESI-MS $m / z$ : Calcd for $\mathrm{C}_{10} \mathrm{H}_{8} \mathrm{FNO}_{2} \mathrm{~S}: 226.03[\mathrm{M}+\mathrm{H}]^{+}$; found: 226.08 . $[\alpha]_{\mathrm{D}}^{20}+25.3^{\circ}$ $(c=0.1, \mathrm{MeOH})$.

(S)-2-(4'-Bromophenyl)-4-carboxy-4,5-dihydrothiazole (4a). White power. m.p. $194-196{ }^{\circ} \mathrm{C} .{ }^{1} \mathrm{H}-\mathrm{NMR}$ $\left(\mathrm{CDCl}_{3}\right) \delta 7.74-7.72(\mathrm{~m}, 2 \mathrm{H}), 7.59-7.58(\mathrm{~m}, 2 \mathrm{H}), 5.35(\mathrm{t}, J=9.6 \mathrm{~Hz}, 1 \mathrm{H}), 3.76(\mathrm{~d}, J=9.8 \mathrm{~Hz}, 2 \mathrm{H})$. ${ }^{13} \mathrm{C}-\mathrm{NMR}\left(\mathrm{CDCl}_{3}\right) \delta 172.5,171.9,132.0 \times 2,130.9,130.0 \times 2,127.0,78.0,35.2$. ESI-MS $m / z$ : Calcd for $\mathrm{C}_{10} \mathrm{H}_{8} \mathrm{BrNO}_{2} \mathrm{~S}: 285.95: 287.95=1: 1[\mathrm{M}+\mathrm{H}]^{+}$; found: $285.91: 287.75=1: 1 .[\alpha]_{\mathrm{D}}^{20}+14.6^{\circ}(c=0.1, \mathrm{MeOH})$.

(S)-2-(3'-Hydroxyphenyl)-4-carboxy-4,5-dihydrothiazole $(\mathbf{5 a}) . \quad$ Yellow oil. $\quad[\alpha]_{\mathrm{D}}^{20}+13.3^{\circ} \quad(c=0.1$, $\mathrm{MeOH})[14]$.

(S)-2-(3'-Methylphenyl)-4-carboxy-4,5-dihydrothiazole (6a). Yellow power. m.p. $118-120{ }^{\circ} \mathrm{C} .{ }^{1} \mathrm{H}-\mathrm{NMR}$ $\left(\mathrm{CDCl}_{3}\right) \delta 7.66($ br. $\quad \mathrm{s}, 1 \mathrm{H}), 7.64-7.49(\mathrm{~m}, 1 \mathrm{H}), 7.48-7.27(\mathrm{~m}, 2 \mathrm{H}), 5.25(\mathrm{t}, J=9.1 \mathrm{~Hz}, 1 \mathrm{H})$, 3.70-3.61 (m, 2H), $2.36(\mathrm{~s}, 3 \mathrm{H}) .{ }^{13} \mathrm{C}-\mathrm{NMR}\left(\mathrm{CDCl}_{3}\right) \delta 172.6,172.0,138.2,132.5,132.2,128.8,128.3$, 125.6, 78.0, 35.0, 21.0. ESI-MS $m / z$ : Calcd for $\mathrm{C}_{11} \mathrm{H}_{11} \mathrm{NO}_{2} \mathrm{~S}: 222.05[\mathrm{M}+\mathrm{H}]^{+}$; found: 222.33 . $[\alpha]_{\mathrm{D}}^{20}+30.2^{\circ}(c=0.1, \mathrm{MeOH})$.

(S)-2-(2'-Hydroxyphenyl)-4-carboxy-4,5-dihydrothiazole (7a). Yellow solid. m.p. $\quad{ }^{128-130}{ }^{\circ} \mathrm{C}$. $[\alpha]_{\mathrm{D}}^{20}+159.9^{\circ}(c=0.1, \mathrm{MeOH})[15]$.

(S)-2-(2'-Fluorophenyl)-4-carboxy-4,5-dihydrothiazole (8a). Yellow oil. ${ }^{1} \mathrm{H}-\mathrm{NMR}$ (DMSO- $\left.d_{6}\right) \delta 7.90-7.87$ $(\mathrm{m}, 1 \mathrm{H}), 7.69-7.57(\mathrm{~m}, 2 \mathrm{H}), 7.31-7.27(\mathrm{~m}, 1 \mathrm{H}), 5.26(\mathrm{t}, J=9.0 \mathrm{~Hz}, 1 \mathrm{H}), 3.73-3.68(\mathrm{~m}, 1 \mathrm{H}), 3.63-3.59$ (m, 1H). ${ }^{13}$ C-NMR (DMSO- $\left.d_{6}\right) \delta 171.7,171.4,163.1(\mathrm{~d}, J=3.78 \mathrm{~Hz}), 133.6(\mathrm{~d}, J=7.56 \mathrm{~Hz}), 130.3(\mathrm{~d}$, $J=1.26 \mathrm{~Hz}), 124.9(\mathrm{~d}, J=2.52 \mathrm{~Hz}), 120.2(\mathrm{~d}, J=7.56 \mathrm{~Hz}), 116.6(\mathrm{~d}, J=8.82 \mathrm{~Hz}), 77.2,35.0(\mathrm{~d}, J=5.04 \mathrm{~Hz})$. ESI-MS $m / z$ : Calcd for $\mathrm{C}_{11} \mathrm{H}_{11} \mathrm{NO}_{2} \mathrm{~S}: 226.03[\mathrm{M}+\mathrm{H}]^{+}$; found: $226.03 .[\alpha]_{\mathrm{D}}^{20}+96.8^{\circ}(c=0.1, \mathrm{MeOH})$.

(S)-2-(2'-Chlorophenyl)-4-carboxy-4,5-dihydrothiazole (9a). Yellow solid. m.p. 120-122 ${ }^{\circ} \mathrm{C} .{ }^{1} \mathrm{H}-\mathrm{NMR}$ $\left(\mathrm{CDCl}_{3}\right) \delta 7.63(\mathrm{~d}, J=7.6 \mathrm{~Hz}, 1 \mathrm{H}), 7.46-7.43(\mathrm{~m}, 1 \mathrm{H}), 7.39(\mathrm{~d}, J=7.9 \mathrm{~Hz}, 1 \mathrm{H}), 7.32-7.28(\mathrm{~m}, 1 \mathrm{H})$, $5.38(\mathrm{t}, J=9.5 \mathrm{~Hz}, 1 \mathrm{H}), 3.92-3.68(\mathrm{~m}, 2 \mathrm{H}) .{ }^{13} \mathrm{C}-\mathrm{NMR}\left(\mathrm{CDCl}_{3}\right) \delta 173.1,171.4,132.5,131.8,131.5,130.8$, 130.6, 126.9, 77.5, 36.0. ESI-MS $m / z$ : Calcd for $\mathrm{C}_{10} \mathrm{H}_{8} \mathrm{ClNO}_{2} \mathrm{~S}: 242.00: 244.00=3: 1[\mathrm{M}+\mathrm{H}]^{+}$; found: 242.36:244.48 = 3:1. $[\alpha]_{\mathrm{D}}^{20}+62.6^{\circ}(c=0.1, \mathrm{MeOH})$.

(S)-2-(2'-Bromophenyl)-4-carboxy-4,5-dihydrothiazole (10a). Yellow oil. ${ }^{1} \mathrm{H}-\mathrm{NMR}\left(\mathrm{CDCl}_{3}\right) \delta 7.65(\mathrm{~d}$, $J=8.2 \mathrm{~Hz}, 1 \mathrm{H}), 7.59-7.54(\mathrm{~m}, 1 \mathrm{H}), 7.38-7.22(\mathrm{~m}, 2 \mathrm{H}), 5.41(\mathrm{t}, J=9.5 \mathrm{~Hz}, 1 \mathrm{H}), 3.87-3.76(\mathrm{~m}, 2 \mathrm{H})$. ${ }^{13} \mathrm{C}-\mathrm{NMR}\left(\mathrm{CDCl}_{3}\right) \delta 172.6,167.5,133.9,131.9,130.6,129.7,127.4,121.2,77.8,36.1$. ESI-MS $\mathrm{m} / \mathrm{z}$ : Calcd for $\mathrm{C}_{10} \mathrm{H}_{8} \mathrm{BrNO}_{2} \mathrm{~S}: 285.95: 287.95=1: 1[\mathrm{M}+\mathrm{H}]^{+}$; found: $285.87: 287.92=1: 1 . \quad[\alpha]_{\mathrm{D}}^{20}+74.5^{\circ}$ $(c=0.1, \mathrm{MeOH})$.

(R)-2-Phenyl-4-carboxy-4,5-dihydrothiazole (1a'). Yellow powder. m.p. $116-118{ }^{\circ} \mathrm{C} .{ }^{1} \mathrm{H}-\mathrm{NMR}\left(\mathrm{CDCl}_{3}\right) \delta$ $7.83(\mathrm{~d}, J=7.6 \mathrm{~Hz}, 2 \mathrm{H}), 7.48-7.45(\mathrm{~m}, 1 \mathrm{H}), 7.40-7.38(\mathrm{~m}, 2 \mathrm{H}), 5.26(\mathrm{t}, J=9.1 \mathrm{~Hz}, 1 \mathrm{H}), 3.72-3.64(\mathrm{~m}, 2 \mathrm{H})$. ${ }^{13} \mathrm{C}-\mathrm{NMR}\left(\mathrm{CDCl}_{3}\right) \delta 172.6,171.8,132.4,131.7,128.9 \times 2,128.1 \times 2,78.1,35.1$. ESI-MS $m / z$ : Calcd for $\mathrm{C}_{10} \mathrm{H}_{9} \mathrm{NO}_{2} \mathrm{~S}: 208.04[\mathrm{M}+\mathrm{H}]^{+}$; found: 208.26. $[\alpha]_{\mathrm{D}}^{20}-10.5^{\circ}(c=0.1, \mathrm{MeOH})$.

(R)-2-(4'-Hydroxyphenyl)-4-carboxy-4,5-dihydrothiazole (2a'). White solid. m.p. $150-152^{\circ} \mathrm{C} .[\alpha]_{\mathrm{D}}^{20}-12 \cdot 5^{\circ}$ $(c=0.1, \mathrm{MeOH})[13]$.

(R)-2-(4'-Fluorophenyl)-4-carboxy-4,5-dihydrothiazole (3a'). White solid. m.p. $120-122{ }^{\circ} \mathrm{C} .{ }^{1} \mathrm{H}-\mathrm{NMR}$ $\left(\mathrm{CDCl}_{3}\right) \delta 10.23$ (br. s, $\left.1 \mathrm{H}\right), 7.86(\mathrm{dd}, J=5.4,8.5 \mathrm{~Hz}, 2 \mathrm{H}), 7.13-7.09(\mathrm{~m}, 2 \mathrm{H}), 5.41-5.37(\mathrm{~m}, 1 \mathrm{H})$, 
3.78-3.69 (m, 2H). ${ }^{13} \mathrm{C}-\mathrm{NMR}\left(\mathrm{CDCl}_{3}\right) \delta 173.7,172.0,165.1(\mathrm{~d}, J=252 \mathrm{~Hz}), 130.9,130.9,128.3,115.9$, 115.7, 77.5, 35.3. ESI-MS $m / z$ : Calcd for $\mathrm{C}_{10} \mathrm{H}_{8} \mathrm{FNO}_{2} \mathrm{~S}: 226.04[\mathrm{M}+\mathrm{H}]^{+}$; found: $226.33 .[\alpha]_{\mathrm{D}}^{20}-25.3^{\circ}$ $(c=0.1, \mathrm{MeOH})$.

(R)-2-(4'-Bromophenyl)-4-carboxy-4,5-dihydrothiazole (4a'). White power. m.p. $194-196{ }^{\circ} \mathrm{C} .{ }^{1} \mathrm{H}-\mathrm{NMR}$ $\left(\right.$ DMSO- $\left._{6}\right) \delta 7.85-7.66(\mathrm{~m}, 4 \mathrm{H}), 5.31(\mathrm{t}, J=8.8 \mathrm{~Hz}, 1 \mathrm{H}), 3.84-3.70(\mathrm{~m}, 1 \mathrm{H}), 3.70-3.59(\mathrm{~m}, 1 \mathrm{H}) .{ }^{13} \mathrm{C}-\mathrm{NMR}$ $\left(\right.$ DMSO- $\left.d_{6}\right) \delta 171.6,167.3,131.9 \times 2,131.4,130.0 \times 2,125.4,78.4,35.2$. ESI-MS $m / z$ : Calcd for $\mathrm{C}_{10} \mathrm{H}_{8} \mathrm{BrNO}_{2} \mathrm{~S}: 285.95: 287.95=1: 1[\mathrm{M}+\mathrm{H}]^{+}$; found: 285.92:287.86 = 1:1. $[\alpha]_{\mathrm{D}}^{20}-14.6^{\circ}(c=0.1, \mathrm{MeOH})$.

(R)-2-(3'-Hydroxyphenyl)-4-carboxy-4,5-dihydrothiazole $\left(\mathbf{5 a}^{\prime}\right) . \quad$ Yellow oil. $\quad[\alpha]_{\mathrm{D}}^{20}-13.3^{\circ} \quad(c=0.1$, $\mathrm{MeOH})[14]$.

(R)-2-(3'-Methylphenyl)-4-carboxy-4,5-dihydrothiazole (6a'). Yellow power. m.p. $118-120{ }^{\circ} \mathrm{C} .{ }^{1} \mathrm{H}-\mathrm{NMR}$ $\left(\mathrm{CDCl}_{3}\right) \delta 7.67$ (br. s, 1H), 7.64-7.54 (m, 1H), 7.40-7.27 (m, 2H), $5.25(\mathrm{t}, J=9.1 \mathrm{~Hz}, 1 \mathrm{H}), 3.77-3.56(\mathrm{~m}$, 2H), $2.36(\mathrm{~s}, 3 \mathrm{H}) .{ }^{13} \mathrm{C}-\mathrm{NMR}\left(\mathrm{CDCl}_{3}\right) \delta 172.6,172.0,138.2,132.5,132.3,128.9,128.3,125.7,78.0,35.0,21.0$. ESI-MS $m / z$ : Calcd for $\mathrm{C}_{11} \mathrm{H}_{11} \mathrm{NO}_{2} \mathrm{~S}: 222.05[\mathrm{M}+\mathrm{H}]^{+}$; found: 222.27. $[\alpha]_{\mathrm{D}}^{20}-30.2^{\circ}(c=0.1, \mathrm{MeOH})$.

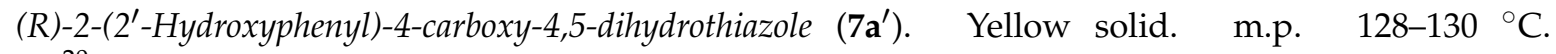
$[\alpha]_{\mathrm{D}}^{20}-160.0^{\circ}(c=0.1, \mathrm{MeOH})[15]$.

(R)-2-(2'-Fluorophenyl)-4-carboxy-4,5-dihydrothiazole (8a'). Yellow oil. ${ }^{1} \mathrm{H}-\mathrm{NMR}$ (DMSO-d $\left.\mathrm{d}_{6}\right) \delta 7.90-7.87$ $(\mathrm{m}, 1 \mathrm{H}), 7.69-7.57(\mathrm{~m}, 2 \mathrm{H}), 7.31-7.27(\mathrm{~m}, 1 \mathrm{H}), 5.26(\mathrm{t}, J=9.0 \mathrm{~Hz}, 1 \mathrm{H}), 3.73-3.68(\mathrm{~m}, 1 \mathrm{H}), 3.63-3.59$ (m, 1H). ${ }^{13}$ C-NMR (DMSO- $\left.d_{6}\right) \delta 171.7,171.4,163.1(\mathrm{~d}, J=3.78 \mathrm{~Hz}), 133.6(\mathrm{~d}, J=7.56 \mathrm{~Hz}), 130.3(\mathrm{~d}$, $J=1.26 \mathrm{~Hz}), 124.9(\mathrm{~d}, J=2.52 \mathrm{~Hz}), 120.2(\mathrm{~d}, J=7.56 \mathrm{~Hz}), 116.6(\mathrm{~d}, J=8.82 \mathrm{~Hz}), 77.2,35.0(\mathrm{~d}, J=5.04 \mathrm{~Hz})$. ESI-MS $m / z$ : Calcd for $\mathrm{C}_{10} \mathrm{H}_{8} \mathrm{FNO}_{2} \mathrm{~S}: 226.03[\mathrm{M}+\mathrm{H}]^{+}$; found: 226.18 . $[\alpha]_{\mathrm{D}}^{20}-96.8^{\circ}(c=0.1, \mathrm{MeOH})$.

(R)-2-(2'-Chlorophenyl)-4-carboxy-4,5-dihydrothiazole (9a'). Yellow solid. m.p. 120-122 ${ }^{\circ} \mathrm{C} .{ }^{1} \mathrm{H}-\mathrm{NMR}$ $\left(\mathrm{CDCl}_{3}\right) \delta 7.63(\mathrm{~d}, J=7.6 \mathrm{~Hz}, 1 \mathrm{H}), 7.46-7.43(\mathrm{~m}, 1 \mathrm{H}), 7.39(\mathrm{~d}, J=7.9 \mathrm{~Hz}, 1 \mathrm{H}), 7.32-7.28(\mathrm{~m}, 1 \mathrm{H})$, $5.38(\mathrm{t}, J=9.5 \mathrm{~Hz}, 1 \mathrm{H}), 3.92-3.68(\mathrm{~m}, 2 \mathrm{H}) .{ }^{13} \mathrm{C}-\mathrm{NMR}\left(\mathrm{CDCl}_{3}\right) \delta 173.1,171.4,132.5,131.8,131.5,130.8$, 130.6, 126.9, 77.5, 36.0. ESI-MS $m / z$ : Calcd for $\mathrm{C}_{10} \mathrm{H}_{8} \mathrm{ClNO}_{2} \mathrm{~S}: 242.00: 244.00=3: 1[\mathrm{M}+\mathrm{H}]^{+}$; found: 242.06:244.12 = 3:1. $[\alpha]_{\mathrm{D}}^{20}-62.6^{\circ}(c=0.1, \mathrm{MeOH})$.

(R)-2-(2'-bromophenyl)-4-carboxy-4,5-dihydrothiazole (10a'). Yellow oil. ${ }^{1} \mathrm{H}-\mathrm{NMR}\left(\mathrm{CDCl}_{3}\right) \delta 7.65(\mathrm{~d}$, $J=8.2 \mathrm{~Hz}, 1 \mathrm{H}), 7.59-7.54(\mathrm{~m}, 1 \mathrm{H}), 7.38-7.22(\mathrm{~m}, 2 \mathrm{H}), 5.41(\mathrm{t}, J=9.5 \mathrm{~Hz}, 1 \mathrm{H}), 3.87-3.76(\mathrm{~m}, 2 \mathrm{H})$. ${ }^{13} \mathrm{C}-\mathrm{NMR}\left(\mathrm{CDCl}_{3}\right) \delta 172.6,167.5,133.9,131.9,130.6,129.7,127.4,121.2,77.8,36.1$. ESI-MS $\mathrm{m} / z$ : Calcd for $\mathrm{C}_{10} \mathrm{H}_{8} \mathrm{BrNO}_{2} \mathrm{~S}: 285.95: 287.95=1: 1[\mathrm{M}+\mathrm{H}]^{+}$; found: $285.87: 287.69=1: 1 . \quad[\alpha]_{\mathrm{D}}^{20}-74.5^{\circ}$ $(c=0.1, \mathrm{MeOH})$.

\subsection{Biology}

\subsubsection{Filter Paper Assay}

The standard bacterial stains were provided by the Institute of Plant Disease, Northwest Agriculture and Forestry University. Ampicillin (Sigma, Shanghai, China) was preferred as the positive control. Mueller-Hinton (Hangzhou Microbial Reagent Co., Ltd., Hangzhou, China) agar was used as an assay medium. The medium at $45^{\circ} \mathrm{C}$ was mixed with a suspension containing the bacterial pathogen at approximately 108 colony forming units $(\mathrm{CFU}) \cdot \mathrm{mL}^{-1}$. Petri dishes $(9 \mathrm{~cm}$ in diameter) were then flooded with the mixture. The tested samples were dissolved in acetone at the concentration of $1000 \mathrm{ppm}$, the filter papers ( $6 \mathrm{~mm}$ in diameter) were impregnated with $10 \mu \mathrm{L} /$ disc of each compound, then were completely dried and placed on the inoculated agar. The inoculated plates were incubated at $37^{\circ} \mathrm{C}$ for $10-12 \mathrm{~h}$. Antibacterial activity was evaluated by measuring the zone of inhibition against the test organism. Experiments were run in triplicate. 


\subsubsection{Minimal Inhibitory Concentration (MIC)}

Antibacterial activities were measured by the micro-broth dilution method in 96-well culture plates using the Mueller-Hinton broth, according to the National Committee for Clinical Laboratory Standards. The tested bacteria were incubated in the Mueller-Hinton broth for $12 \mathrm{~h}$ at $37^{\circ} \mathrm{C}$ at $190 \mathrm{rpm}$, and the spore concentration was diluted to approximately $1 \times 10^{5}-1 \times 10^{6} \mathrm{CFU} / \mathrm{mL}$ with Mueller-Hinton broth. After incubation for $24 \mathrm{~h}$ at $37^{\circ} \mathrm{C}$, the MICs were examined by observing the first few holes transparent [3].

\subsubsection{The Fatty Acid Exposure Experiment}

The medium at $45{ }^{\circ} \mathrm{C}$ was mixed with a suspension containing the bacterial pathogen at approximately $108 \mathrm{CFU} \cdot \mathrm{mL}^{-1}$ and fatty acid or fatty acid salt of certain concentration gradient. Petri dishes $(9 \mathrm{~cm}$ in diameter) were then flooded with the mixture. Compound $\mathbf{7 h}$ was dissolved in acetone at the concentration of $100 \mathrm{ppm}$, the filter papers (6 $\mathrm{mm}$ in diameter) were impregnated with $10 \mu \mathrm{L} /$ disc of each compound. The inoculated plates were incubated at $37^{\circ} \mathrm{C}$ for $10-12 \mathrm{~h}$. The fatty acid added experiment was evaluated by measuring the zone of inhibition against the test organism. The experiments were run in triplicate.

\subsubsection{Scanning Electron Microscopy}

The tested bacteria were incubated in the Mueller-Hinton broth for $12 \mathrm{~h}$ at $37^{\circ} \mathrm{C}$ at $180 \mathrm{rpm}$ and the spore concentration was diluted to approximately $1 \times 10^{5}-1 \times 10^{6} \mathrm{CFU} / \mathrm{mL}$ with Mueller-Hinton broth. Compound $7 \mathrm{~h}$ was dissolved in acetone and added to the broth. After incubation for $2 \mathrm{~h}$ at $37^{\circ} \mathrm{C}$ then centrifuged at $3500 \mathrm{rpm}$ for $20 \mathrm{~min}$. All the cells were washed twice with $0.1 \mathrm{M}$ phosphate buffer saline (PBS, pH 7.4) and fixed with 2.5\% glutaraldehyde $(v / v)$ in $0.1 \mathrm{M}$ PBS at $4{ }^{\circ} \mathrm{C}$ for $24 \mathrm{~h}$. Next, the cells were dehydrated using 30\%,50\%,70\%, 90\%, and 100\% ethanol, and then the ethanol was replaced by tertiary butyl alcohol. The cells were dried at "critical point" in liquid $\mathrm{CO}_{2}$, and the samples were gold-covered by cathodic spraying before examination $[16,17]$.

\section{Conclusions}

Aryl nitriles and methyl cysteine reacted in the presence of sodium carbonate in dry methanol to afford methyl-2-aryl-4, 5-dihydrothiazole-4-carboxylates in high yield. Ortho substituents did not favor the reaction, especially some large groups, such as $-\mathrm{Br}$ and $-\mathrm{Cl}$. Meanwhile electron-withdrawing groups were better to this reaction than electron-donating ones.

Not only electron-withdrawing but also electron-donating groups could diminish the antibacterial activities unless a 2'-hydroxy was present in the 2-aryl substituent of the 4,5-dihydro-thiazole analogues. These results implied that the intramolecular hydrogen bond between the $2^{\prime}$-hydroxy and the nitrogen-atom of 4,5-dihydrothiazole is very important for the antibacterial activities of these compounds.

According to the fatty acid exposure experiments at high concentrations of fatty acid (1000 ppm), when short chain acids were added in culture medium, the bacteria grew normally; inhibition zones become small while long chain acids were added in it. The overall trend is consistent with the results of yanglingmycin, whereby by decreasing the concentration of fatty acids added, the inhibition zone gradually increased. This implied that these antibacterial compounds influence fatty acid synthesis of the tested bacteria. Scanning electron microscopy results showed that the bacterial cell walls showed depressions, leading to cell content leakage. Compound $7 \mathrm{~h}$ may damage cell membranes, leading to altered cell metabolism and the finally cell lysis and death. The antibacterial mechanism is similar to that of yanglingmycin.

Acknowledgments: This work was supported by the National Natural Science Foundation of China (31371958, 31070344, 21372185) and Agricultural Science and Technology Research Foundation of Shanxi Province (2014k02-10-02). 
Author Contributions: F.T., B.S. and J.Z. designed research; F.T. performed research; B.S., J.L. and W.W. performed statistical analysis; F.T. and J.Z. wrote the paper; B.S. and W.W. reviewed the manuscript.

Conflicts of Interest: The authors declare no conflict of interest.

\section{References}

1. Mansfield, J.; Genin, S. Top 10 plant pathogenic bacteria in molecular plant pathology. Mol. Plant Pathol. 2012, 13, 614-629. [CrossRef] [PubMed]

2. Zhang, J.W.; Zhang, W.J. A new dihydrooxazole antibiotic from the fermentation broth of streptomyces djakartensis. Heterocycles 2014, 89, 1656-1661.

3. Li, L.B.; Dan, W.J.; Tan, F.F.; Cui, L.H. Synthesis and antibacterial activities of Yanglingmycin analogues. Chem. Pharm. Bull. 2015, 63, 33-37. [CrossRef] [PubMed]

4. Wu, W.J.; Zhang, J.W.; Zhang, W.J. A new dihydrooxazole antibiotic: structure, bioactivity and mechanism. In Proceedings of the International Conference on Biopesticides 7, Side-Antalya, Turkey, 19-25 October 2014; p. 145.

5. Zhang, W.J.; Wei, S.P.; Zhang, J.W.; Wu, W.J. Antibacterial activity composition of the fermentation broth of Streptomyces djakartensis NW35. Molecules 2013, 18, 2763-2768. [CrossRef] [PubMed]

6. Zamri, A.; Abdallah, M.A. An improved stereocontrolled synthesis of pyochelin, siderophore of Pseudomonas aeruginosa and Burkholderia cepacia. Tetrahedron 2000, 56, 249-256. [CrossRef]

7. Inahashi, Y.; Iwatsuki, M.; Ishiyama, A.; Namatame, M.; Nishihara-Tsukashima, A.; Matsumoto, A.; Hirose, T.; Sunazuka, T.; Yamada, H.; Otoguro, K.; et al. Spoxazomicins A-C, novel antitrypanosomal alkaloids produced by an endophytic actinomycete, Streptosporangium oxazolinicum K07-0460T. J. Antibiot. 2011, 64, 303-307. [CrossRef] [PubMed]

8. Fernandez, X.; Fellous, R.; Duñach, E. Novel synthesis of 2-thiazolines. Tetrahedron Lett. 2000, 41, 3381-3384. [CrossRef]

9. Ino, A.; Hasegawa, Y.; Murabayashi, A. Total synthesis of the antimycoplasma antibiotic micacocidin. Tetrahedron Lett. 1998, 39, 3509-3512. [CrossRef]

10. Suzuki, N.; Izawa, Y. A convenient synthesis of 2-phenyl-thiazolines. Tetrahedron Lett. 1974, 15, $1863-1864$. [CrossRef]

11. Kline, T.; Fromhold, M.; McKennon, T.E.; Cai, S.; Treiberg, J.; Ihle, N.; Sherman, D.; Schwan, W.; Hickey, M.J.; Warrener, P.; et al. Antimicrobial Effects of novel siderophores linked to $\beta$-lactam antibiotics. Bioorg. Med. Chem. 2000, 8, 71-93. [CrossRef]

12. Zunnundzhanov, A.; Bessonova, I.A.; Abdullaev, N.D.; Ogai, D.K. Structure of aeruging from Pseudomonas aeruginosa. Chem. Nat. Compd. 1987, 4, 461-465. [CrossRef]

13. Loughlin, W.A.; Knevitt, S.A. Approaches to the high-throughput synthesis of analogues of Dihydroaeruginoic. Acid. Aust. J. Chem. 2000, 53, 457-462. [CrossRef]

14. Maltsev, O.V.; Walter, V. Medium buffer effects on the condensation of L-Cysteine and aryl nitriles to (R)-2-aryl-4,5-dihydrothiazole-4-carboxylic acids. Synthesis 2013, 45, 2763-2767. [CrossRef]

15. Ferm, R.J.; Riebsomer, J.L. The Chemistry of the 2-imidazolines and imidazolidines. Chem. Rev. 1954, 54, 593-613. [CrossRef]

16. Bandyopadhyay, N.; Zhu, M.; Lu, L.; Mitra, D.; Das, M.; Das, P.; Samanta, A.; Naskar, J.P. Synthesis, structure, spectral characterization, electrochemistry and evaluation of antibacterial potentiality of a novel oxime-based palladium(II) compound. Eur. J. Med. Chem. 2015, 89, 59-66. [CrossRef] [PubMed]

17. Sun, D.; Zhang, W.; Lv, M.; Yang, E.; Zhao, Q.; Wang, W. Antibacterial activity of ruthenium(II) polypyridyl complex manipulated by membrane permeability and cell morphology. Bioorg. Med. Chem. Lett. 2015, 25, 2068-2073. [CrossRef] [PubMed]

Sample Availability: Samples of the compounds are available from the authors.

(C) 2015 by the authors; licensee MDPI, Basel, Switzerland. This article is an open access article distributed under the terms and conditions of the Creative Commons by Attribution (CC-BY) license (http://creativecommons.org/licenses/by/4.0/). 